\title{
La adaptación de las lenguas al entorno: una aproximación crítica*
}

\author{
The adaptation of languages to the environment: a critical approach
}

\author{
José-Luis MendíviL-Giró \\ Universidad de Zaragoza \\ jlmendi@unizar.es \\ ORCID iD: 0000-000I-689I-6275
}

Recibíu / Received: 6-IX-20 I 8

Aceptáu / Accepted: I4-II-20I9

RESUMEN. La presente aportación propone una aproximación crítica de las propuestas que postulan que la explicación de la diversidad de las lenguas se sigue de la adaptación de las mismas al entorno extralingüístico. Mostraré que, a pesar de que la comparación entre lenguas y especies naturales es sólida y razonable, la correlación entre propiedades lingüísticas y aspectos extralingüísticos es débil, esencialmente por dos razones: (I) porque buena parte de la estructura de las lenguas no es sensible al cambio lingüístico y, por tanto, no puede adaptarse a nada y (II) porque las partes de la estructura de las lenguas que sí son sensibles al cambio lingüístico en general tienen una relación muy indirecta con el entorno cultural y físico en el que se hablan.

Palabras clave: cambio lingüístico, tipología lingüística, variación, adaptación.

ABSTRACT. The present paper presents a critical review of current approaches postulating that the explanation of language diversity follows from the adaptation of languages to the extralinguistic environment. I show that, despite the comparison between languages and species being sound and reasonable, the correlation between linguistic features and extralinguistic aspects is weak, mainly because of two reasons: (I) a good deal of the structure of languages in not sensitive to linguistic change and, therefore, cannot be adapted, and (II) the parts of the structure of languages which are affected by linguistic changes have a very indirect relation with external factors.

Keywords: linguistic change, language typology, variation, adaptation.

Cómo citar / Form of Citation: Mendívil-Giró, José-Luis (2019): "La adaptación de las lenguas al entorno: una aproximación crítica”, Glosema, I, pp. I39-I75. https://doi.org/I0.178 I I/glosema.I.2019.139-175.

\footnotetext{
*El presente artículo es una versión traducida, revisada y muy ampliada de Mendívil-Giró 2018. Deseo agradecer los comentarios y sugerencias del editor y de los revisores anónimos que han mejorado el manuscrito. La investigación se ha beneficiado de los fondos asignados al proyecto FFI2017-82460-P subvencionado por la Agencia Estatal de Investigación y de la ayuda del Gobierno de Aragón y fondos FEDER al grupo de investigación Psylex (Lenguaje y cognición).
} 


\section{INTRODUCCIÓN: ¿POR QUÉ LAS LENGUAS NO SE ADAPTAN A SU ENTORNO?}

T A idea de que la diversidad de las lenguas existentes podría explicarse como el _resultado de la adaptación de las mismas al entorno (a diferentes entornos, es de suponer) es claramente deudora de la teoría evolutiva, sin duda la mejor explicación científica que existe para explicar y comprender la diversidad de las especies y de los organismos naturales. Mi propuesta en esta aportación es en cierto modo paradójica. Por una parte, voy a argumentar que, en efecto, las lenguas y las especies naturales son objetos naturales histórica/evolutivamente modificados y que, como ya señaló el propio Charles Darwin, sus mecanismos de evolución son "curiosamente paralelos" ("curiosamente los mismos", llegó a escribir) ${ }^{1}$. Pero, por otra parte, también aspiro a mostrar que la reciente moda de establecer correlaciones entre propiedades estructurales de las lenguas y el entorno extralingüístico (véanse síntesis recientes en De Busser y LaPolla 2015, Ladd et al. 2015 y Lupyan y Dale 2016) es insuficiente para explicar tanto la estructura de las lenguas como su tipología.

De hecho, la evaluación de la afirmación de que las lenguas se adaptan al entorno depende crucialmente de cómo definamos lengua, adaptación y entorno, así como de cómo concibamos la propia teoría evolutiva. Si definimos adaptación como el resultado de una transmisión diferencial de rasgos fenotípicos por medio de la selección de ciertos rasgos, entonces es indudable que tanto las lenguas como las especies se adaptan a su entorno. Sin embargo, si el concepto de 'adaptación' implica que el entorno es la fuente esencial de la estructura de los objetos en evolución, entonces es posible decir que ni las lenguas ni las especies naturales se adaptan al entorno. El reconocimiento de que lenguas y especies son semejantes en sus mecanismos de cambio no implica que haya una única manera de interpretar la relación entre la estructura de un objeto y el entorno en el que evoluciona, tanto en biología evolutiva como en lingüística histórica.

En los apartados siguientes consideraré qué sentidos de las nociones de lengua, adaptación y entorno son los que permiten concluir que las lenguas no se adaptan al entorno. Más específicamente, mostraré que en el caso de las lenguas buena parte de su estructura es insensible al cambio histórico y, por tanto, incapaz de adaptación a entorno alguno. Además, el entorno inmediato de las lenguas es en realidad interno a la mente/cerebro de los hablantes y, por tanto, mucho menos variable

\footnotetext{
1 "The formation of different languages and of distinct species, and the proofs that both have been developed through a gradual process, are curiously the same" (Darwin I87I: 59). La edición revisada de I874 y las posteriores dicen "curiously parallel".
} 
que los entornos físicos y sociales en los que viven las personas. Por otra parte, las dimensiones de la estructura de las lenguas que sí son variables tienen una relación tan indirecta con tales entornos sociales y físicos que la noción de adaptación a la realidad extralingüística solo se puede entender en un sentido débil y poco informativo respeto de la explicación de la tipología estructural de las leguas.

\section{LA COMPARACIÓN ENTRE LENGUAS Y ESPECIES}

Siguiendo la visión de August Schleicher, el primer gran lingüista que abordó la analogía entre lenguas y especies introducida por Darwin, asumiré que "not a word of Darwin's need be changed here if we wish to apply this reasoning to languages" (Schleicher I983 [I 863]: 64). La razón de esta asunción es que en ambos casos nos encontramos ante objetos naturales históricamente modificados. De hecho, puede decirse que ambos procesos (el cambio evolutivo y el cambio lingüístico) son formalmente idénticos, aunque puedan ser diferentes substancialmente ( $c f$. Mendívil-Giró 20I4). A pesar de que son muchas las propuestas que se han hecho sobre cuáles serían los términos adecuados de la comparación ( $c f$., por ejemplo, Croft 2000 para una elaborada propuesta y Mendívil-Giró 2006 para una crítica y una propuesta alternativa), la más apropiada es, en mi opinión, la que formuló el propio Schleicher en su reseña a la primera edición en alemán de El origen de las especies de Darwin:

The species of a genus are what we call the languages of a family, the races of a species are with us the dialects of a language; the sub-dialects or patois correspond with the varieties of the species, and that which is characteristic of a person's mode of speaking corresponds with the individual. (Schleicher 1983 [1863]: 32)

Eso que Schleicher denomina aquello que es característico del modo de hablar de una persona y que equipara al individuo (el organismo) es lo más cercano al concepto chomskiano de 'lengua-i' (lengua interna) que se podía formular en aquella época. La distinción entre lengua-i y lengua-e (lengua externa) propuesta por Chomsky (1985) estaba orientada a aclarar que el objeto de estudio de la lingüística entendida como parte de la ciencia cognitiva no es un objeto externo, un código compartido ni una institución social, sino un estado, una propiedad de la mente/cerebro del hablante. Si adoptamos este punto de vista, es posible argumentar que los términos de comparación más adecuados en la analogía entre lenguas y especies naturales serían los siguientes: el equivalente del organismo natural (el individuo, por ejemplo, un tigre) sería la lengua-i, mientras que el equivalente de la especie (el conjunto de individuos semejantes, por ejemplo, la especie de los tigres) sería un conjunto de lenguas-i semejantes, esto es, lo que normalmente llamamos una 
lengua. Así, en este contexto, una lengua como el español no sería sino el conjunto de leguas-i de las personas que hablan español (esto es, de aquellos hablantes que identificamos como hablantes del español), del mismo modo que la especie de los tigres no es sino el conjunto de individuos que identificamos como tigres. En ambos casos el criterio de delimitación, basado en el grado de semejanza, es difuso y en cierta medida arbitrario. En el caso de las especies se emplea el criterio de reproducción fértil (Mayr 1942) y en el caso de las lenguas el criterio de inteligibilidad mutua (Dixon 1997). Lo relevante es que tanto las especies naturales como las lenguas (entendidas como conjunto de lenguas-i similares) son grupos de individuos semejantes. Una especie natural está hecha de individuos "suficientemente similares”. Un orangután y un ser humano tienen más en común entre sí que con una vaca, pero los tres pertenecen a especies diferentes. Sabemos que la mayor semejanza entre un orangután y un ser humano se debe a que su ancestro común es mucho más reciente (de hace unos 6 millones de años) que el que tienen con la vaca (de varias decenas de millones de años). Una "especie lingüística" (una lengua en el uso normal del término) consiste en individuos (lenguas-i) "suficientemente similares". Así, el equivalente lingüístico de un individuo orgánico (por ejemplo, un tigre) es el órgano del lenguaje (la lengua-i) de una persona, mientras que el equivalente lingüístico de la especie de los tigres (Panthera tigris) es el agrupamiento de tales individuos. Y del mismo modo, el español y el francés se parecen más entre sí que al ruso, pero las tres son lenguas diferentes, y sabemos que la mayor similitud entre el español y el francés se debe a que su ancestro común (de unos I 500 años) es más reciente que el ancestro común con el ruso (de hace unos 6000 años).

Si una lengua-i es el órgano del leguaje de una persona (su facultad del lenguaje), entonces no hay unas 6000 lenguas en el mundo, sino miles de millones, tantos como personas hay (y, de hecho, muchas más, siendo el bilingüismo un rasgo común entre los humanos). Lo único que tiene existencia desde el punto de vista internista, cognitivo, que estamos adoptando, son esos miles de millones de lenguas-i, mientras que todo lo demás (variedades, dialectos, lenguas, familias, etc.) son constructos abstractos que hacemos agrupando las lenguas-i de acuerdo con su semejanza y origen histórico. Y lo mismo es cierto en el ámbito natural: lo que existen son los estados de la materia que llamamos organismos o formas de vida (los billones de animales, plantas, hongos, bacterias, etc., que pueblan el planeta), mientras que las variedades, especies, familias, reinos, etc. son constructos abstractos que elaboramos en función de la semejanza morfológica y genética.

Y así como no diríamos que los tigres son manifestaciones o realizaciones de la especie de los tigres (que tendría una existencia independiente), tampoco es apropiado en este contexto afirmar que las lenguas-i son manifestaciones o realizaciones 
del español o del ruso (que tendrían existencia independiente en gramáticas, en diccionarios o en comunidades sociales). El giro cognitivo iniciado por Chomsky tuvo como fundamento central la visión de que las lenguas humanas no son exclusivamente objetos sociales que los seres humanos aprenden, usan y transmiten de generación en generación, sino que son de hecho diferentes estados (históricamente modificados) de la misma facultad del lenguaje, un atributo específico de la cognición humana. De manera similar, los organismos naturales son diferentes estados (históricamente modificados) del mismo fenómeno bioquímico: la vida ${ }^{2}$.

Es muy relevante tener en cuenta en este punto que el curioso paralelismo entre la evolución natural y el cambio lingüístico no se limita a las interesantes observaciones hechas por Darwin (I 87I), sino que se extiende a los propios ámbitos de estudio (la teoría evolutiva y la lingüística histórica). Así, Gould (2002) analiza en detalle la controversia entre lo que él denomina las teorías adaptacionistas, externistas y funcionalistas de la evolución (el llamado neodarwinismo) frente a los modelos defendidos por teóricos de la evolución anti-neodarwinistas, tales como Brian Goodwin, Stuart Kauffman y el propio Gould. De forma relevante en nuestro contexto, una clave central de las diferencias entre ambos modelos en la historia de la teoría evolutiva moderna es el grado de importancia que se atribuye a la selección natural y a la adaptación al entorno a la hora de explicar la morfología y la estructura de los organismos. Y también puede decirse que en la lingüística histórica ha habido una controversia paralela, en el sentido de que también hay modelos funcionalistas y modelos no funcionalistas (o formalistas) en la teoría del cambio lingüístico ( $c f$. Lass 1997 para una revisión crítica detallada y para una argumentación contra los modelos funcionalistas — adaptativos - del cambio lingüístico). El ímpetu del modelo funcionalista o adaptativo del cambio lingüístico se inicia con los autores del Círculo Lingüística de Praga ( $c f$. Cercle Linguistique de Prague 1929). Característica de esta aproximación es la concepción de las lenguas como instituciones sociales al servicio de la comunicación y la marcada inclinación por las explicaciones teleológicas de los cambios lingüísticos. No resulta ya sorprendente observar que la reemergencia de la concepción teleológica de los cambios lingüísticos coincide en tiempo y en orientación con el surgimiento en los años treinta del siglo XX de la llamada sintesis moderna de la teoría evolutiva (el neodarwinismo). La

\footnotetext{
${ }^{2}$ Lo que hasta el momento he comparado, siguiendo la intuición de Darwin y de Schleicher, son los procesos de cambio lingüístico en las lenguas y de evolución natural en los organismos biológicos. Ello implica que el proceso de evolución del lenguaje como facultad humana sería parte de la evolución natural, y no parte del cambio lingüístico. En otras palabras, se asumirá a partir de ahora que el proceso de cambio lingüístico es el que afecta a las lenguas-i en tiempo histórico (generando diversidad lingüística) y que ese proceso es independiente de los posibles mecanismos evolutivos (en tiempo geológico) que pudieron dar lugar al desarrollo de la facultad del lenguaje en nuestra especie. Cf. Mendívil-Giró 2016 para una discusión de esta asunción y una crítica de los modelos que consideran que el cambio lingüístico sería parte central del proceso de evolución del lenguaje (como facultad humana).
} 
nueva síntesis implicaba una inclinación a considerar la selección natural como el único motor de la evolución natural y a la concepción de que todo rasgo fenotípico tiene que ser adaptativo. Así, el peligro del "panadaptacionismo" seńalado por Gould y otros como una debilidad explicativa del modelo neodarwinista se extiende fácilmente a la lingüística histórica.

Gould (I996) describió la diferencia esencial entre el neodarwinismo y sus alternativas haciendo uso de la metáfora de la bola de billar frente al "poliedro de Galton”. Según el punto de vista neodarwinista, un organismo se podría representar como una bola de billar en movimiento. Cada vez que el taco golpea a la bola ésta se mueve de forma variable e ilimitada en cualquier dirección (dentro del marco de las leyes físicas). El taco que golpea la bola es la selección natural y la bola va allí a donde el taco la lleva. A esto es a lo que Gould se refiere como una teoría evolutiva externista, funcionalista y adaptacionista. Por su parte, el modelo que podría denominarse anti-neodarwinista (asumiendo que anti- no modifica a darwinista, sino a neodarwinista) equipara el organismo a un poliedro que descansa sobre una de sus caras. Una vez que el taco lo golpea, las expectativas de cambio están más restringidas, pues es un poliedro cuya estructura interna limita la variación, de manera que ciertas opciones de cambio serán más probables que otras y algunas serán imposibles, por muy interesantes que pudieran ser adaptativamente.

No es esta la ocasión de revisar la larga disputa sobre el significado y las implicaciones del término adaptación en la teoría evolutiva moderna, ni la de reproducir el debate sobre la canalización de la historia previa y las leyes de la naturaleza "on which natural selection was privileged to work" (Kauffman I993: 643). Sin embargo, sí resulta importante observar que, al adoptar un punto de vista cognitivo en el estudio de las lenguas, no pueden ignorarse las restricciones que el cerebro y la cognición humanos imponen en el diseño estructural de los sistemas de conocimiento que llamamos lenguas, independientemente de aquellos aspectos susceptibles de cambio histórico y, por tanto, candidatos para posibles procesos de adaptación al entorno.

Gould caracterizó la controversia en la teoría evolutiva por medio de la siguiente alternativa:

In what ways does the skewed and partial occupancy of the attainable morphospace of adaptive design record the operation of internal constraints (both negative limitations and positive channels), and not only the simple failure of unlimited number of unconstrained lineages to reach all possible position in the allotted time? (Gould 2002: I053)

Y las dos opciones apuntadas por Gould tienen un equivalente en la teoría lingüística actual. La aproximación internista y formalista (característica de la lingüís- 
tica generativa) concibe las lenguas como sistemas de conocimiento restringidos en su ámbito de variación por la estructura de la facultad del lenguaje humana (esto es, como poliedros de Galton). Esta visión se correlaciona con una concepción "uniformitaria" de la diversidad de las lenguas y con una concepción restrictiva del cambio lingüístico. La aproximación externista y funcionalista (característica de la lingüística cognitivo-funcional) concibe las lenguas como objetos culturales externos que deben su estructura a la adaptación a las necesidades comunicativas y cognitivas de los hablantes (esto es, como bolas de billar). Esta visión se correlaciona con una concepción menos restricta del cambio lingüístico y con un énfasis en la diversidad de las lenguas ( $c f$., por ejemplo, Evans y Levinson 2009).

Mostraré en lo sucesivo que lo que sabemos sobre cómo y cuánto cambian las lenguas en el tiempo y en relación con el entorno nos sitúa en el primer escenario, esto es, aquel en el que la facultad humana del lenguaje restringe estrechamente los aspectos y componentes de las lenguas que pueden variar en el espacio y el tiempo, limitando así los posibles efectos de adaptación al entorno en el diseño de las lenguas.

\section{3. ¿QUÉ ES LO QUE CAMBIA CUANDO CAMBIAN LAS LENGUAS?}

Según la influyente propuesta de Hauser et al. (2002), la facultad humana del lenguaje se podría concebir como un sistema integrado mínimamente por tres componentes: un sistema conceptual-intencional (CI) relacionado con el significado y la interpretación, un sistema sensorio-motor (SM) relacionado con al percepción y producción de señales lingüísticas, y un sistema computacional, responsable de la creación de la estructura sintáctica que subyace a las expresiones lingüísticas y, en última instancia, de la composicionalidad y productividad del lenguaje humano (esto es, la sintaxis en sentido estricto). De acuerdo con desarrollos posteriores de este modelo (Chomsky 2007, Berwick y Chomsky 20I I, 2016), parece razonable pensar que el sistema computacional tiene una relación asimétrica con los dos componentes "externos" (los sistemas CI y SM), de manera que el sistema computacional estaría optimizado para su interacción con el sistema CI, mientras que la relación con el componente SM sería ancilar o secundaria (véase la figura I).

Una implicación crucial de este modelo es que el sistema computacional se empareja con el sistema CI para formar un Lenguaje Interno del Pensamiento (LIP), que sería esencialmente homogéneo en la especie y cuyo diseño evolutivo no estaría orientado a la comunicación, sino hacia el pensamiento ${ }^{3}$. La hipótesis central es que lo que tiene el lenguaje humano de específicamente humano es en buena me-

\footnotetext{
${ }^{3}$ Sobre la hipótesis del lenguaje como un instrumento del pensamiento, $c f$. Asoulin 20 i 6.
} 
dida consecuencia de lo que tiene el pensamiento humano de específicamente humano. Chomsky, de hecho, sugiere que desde un punto de vista evolutivo "the earliest stage of language would have been just that: a language of thought, used internally" (Chomsky 2007: I3).

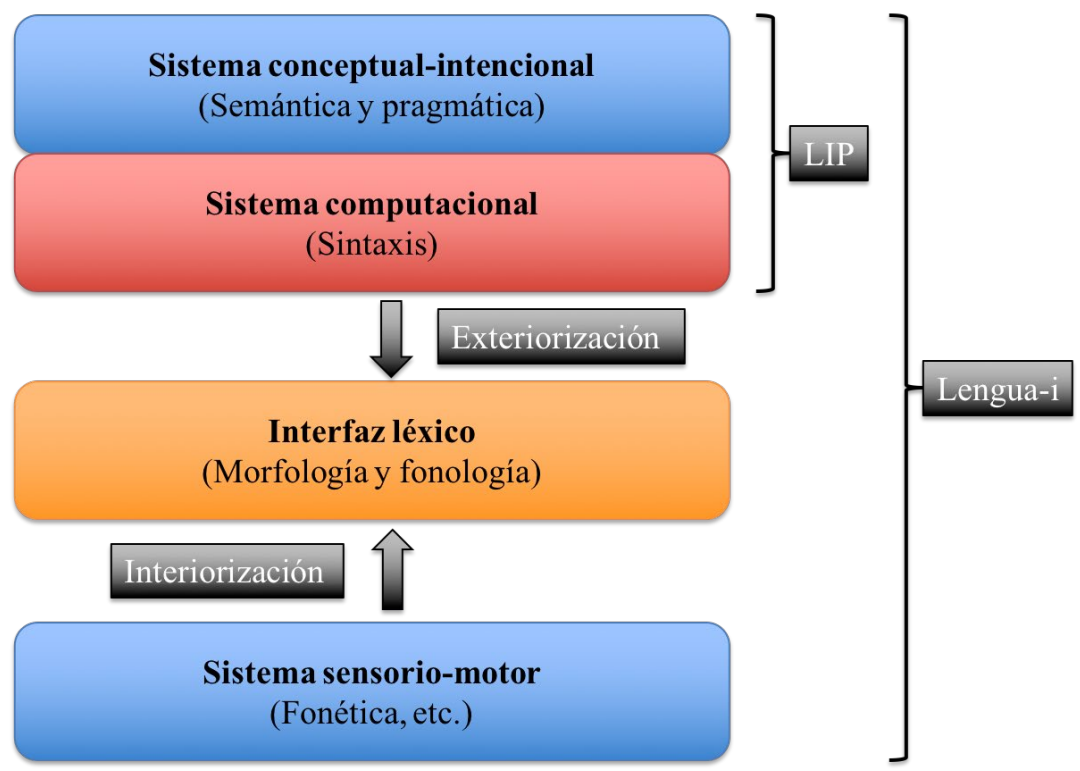

Figura I. La estructura esencial de una lengua-i ${ }^{4}$

La conexión del LIP con el sistema SM es lo que permitiría la "exteriorización” del lenguaje para la interacción y la comunicación con otros. Dado que la conexión del LIP con los sistemas de exteriorización es secundaria, sería precisamente durante ese proceso cuando emergería la principal fuente de la diversidad estructural de las lenguas humanas. Tal y como lo expresan Berwick y Chomsky (20 I : 37-38):

Parameterization and diversity, then, would be mostly — possibly entirely- restricted to externalization. That is pretty much what we seem to find: a computational system efficiently generating expressions interpretable at the semantic/pragmatic interface, with diversity resulting from complex and highly varied modes of externalization, which, furthermore, are readily susceptible to historical change.

\footnotetext{
${ }^{4}$ Figura adaptada de Mendívil-Giró 20r8. Se indica el área tradicional de investigación para cada uno de los componentes. Los componentes principales están relacionados asimétricamente. El componente conceptual-intencional (CI) tiene una conexión directa con el sistema computacional y ambos forman el Lenguaje Interno del Pensamiento (LIP). Este LIP está conectado con el sistema sensorio-motor (SM) para la exteriorización del lenguaje, conexión que se establece a través de una interfaz léxica. La interfaz léxica cambia históricamente durante el proceso de transmisión de la lengua-i de generación en generación.
} 
Así pues, desde esta perspectiva internista, cognitiva, la conexión del LIP con el sistema SM es a la vez lo que permite la exteriorización del lenguaje y lo que, accidentalmente, causa la existencia de diversas lenguas-i. Nótese que partiendo de esta visión se sigue que el mismo LIP subyace a todas las lenguas y que las diferencias entre ellas no están causadas por diferencias esenciales en el sistema CI, en el sistema computacional o en el propio sistema SM (que también está condicionado biológicamente), sino que se seguirían de cómo está conectado el LIP con el sistema SM. En pos de la claridad conceptual, aunque seguramente implique una simplificación, podríamos asumir que la interfaz entre el LIP y el sistema SM es una especie de "léxico", esto es, un repertorio de formantes morfo-fonológicos que permiten la exteriorización en forma de cadenas de morfemas y fonemas (o, en su caso, de signos visuales) de las representaciones sintáctico-semánticas internas producidas por el LIP. El papel de esa interfaz léxica, por tanto, es el de transformar estructuras jerárquicas abstractas en estructuras secuenciales legibles para el sistema SM.

Tal modelo predice que la diversidad de las lenguas-i es el resultado de la variación en el proceso de exteriorización, esto es, de la variación en la configuración de la interfaz léxica de cada lengua-i, tal y como el representado en la figura I. Como se muestra en el diagrama, el desarrollo del lenguaje en cada individuo implica el aprendizaje (la "interiorización") del material léxico necesario para la comunicación. La hipótesis crucial es que es precisamente durante el proceso de aprendizaje de la relación entre formantes morfo-fonológicos y estructuras subyacentes (esto es, de la interfaz léxica) cuando se producen los desajustes o discrepancias que dan lugar a lo que percibimos como cambios lingüísticos y, por tanto, a la diversidad de las lenguas.

El mecanismo esencial de la evolución natural es la mutación genética que produce variación en los fenotipos y de la que se nutre el proceso de selección natural. Sin variación no hay selección posible, ni evolución. Siguiendo la analogía antes revisada, podría decirse que el equivalente de la mutación genética en el lenguaje es el proceso de reanálisis. Podemos definir el reanálisis como una discrepancia en la gramática de dos hablantes en la relación entre, de una parte, una representación interna y, de otra parte, la expresión lingüística de la misma producida por el sistema sensorio-motor ${ }^{5}$.

Consideremos un ejemplo muy simplificado y relativamente burdo para ilustrar este concepto central. En inglés actual el futuro se expresa como una frase (I will

\footnotetext{
${ }^{5}$ Cf. Mendívil-Giró 20 I 5 para un desarrollo de la hipótesis de que el reanálisis es el único mecanismo del proceso de cambio lingüístico.
} 
love 'amaré'), mientras que en español se expresa típicamente como una palabra única (amaré). Según el modelo presentado, la estructura sintáctico-semántica de ambas expresiones sería idéntica o muy similar, mientras que las estructuras morfológicas y fonológicas que las expresan son muy diferentes. En términos de la arquitectura del lenguaje presentada, diríamos que la estructuras semántica y sintáctica (dependientes del sistema CI y del sistema computacional respectivamente) serían muy similares, mientras que la estructuras morfológica y fonológica (dependientes de la interfaz léxica con el sistema SM) serían notablemente diferentes. La hipótesis central es que esas diferencias son consecuencia de cambios lingüísticos (procesos de reanálisis) producidos en la transmisión histórica de sendas interfaces léxicas, de la misma manera que las diferencias entre un orangután y un ser humano son simple consecuencia de diferencias en la selección de mutaciones en sendas estirpes.

Es bien sabido que lo que hoy es un morfema ligado en la morfología flexiva del futuro en español era un verbo auxiliar en estados anteriores de esta lengua (derivados en última instancia de la construcción amare habeo del latín vulgar, una alternativa a la forma sintética del latín clásico amabo). Independientemente ahora de los complejos detalles del proceso, lo relevante es que la transición de una frase (verbo principal + auxiliar) del español anterior a una palabra (raíz + afijo) del español actual necesariamente ha implicado un proceso de reanálisis (una mutación) en la evolución de esta lengua. Así, podríamos decir que para el hablante Hi la expresión E tenía la estructura subyacente Verbo+Auxiliar, mientras que la misma expresión $\mathrm{E}$ para el hablante $\mathrm{H}_{2}$ tenía la representación subyacente Raíz+Afijo, esto es, que el hablante $\mathrm{H}_{2}$ reanalizó la expresión $\mathrm{E}$ confiriéndole una estructura diferente a la que tenía para el hablante Hi. En cierto sentido, pues, la lengua-i del hablante $\mathrm{H}_{2}$ tenía una mutación, puesto que la relación entre los elementos de la expresión E y su estructura subyacente es diferente de la que hay en la lengua-i del hablante $\mathrm{H}_{\mathrm{I}}$.

El oyente (o el niño que aprende una lengua) no tiene acceso inmediato o directo a la estructura sintáctica o a la representación semántica subyacentes a una expresión lingüística cualquiera, sino solo a la onda de sonido que la exterioriza (en el caso de las leguas orales). La tarea del oyente (o del aprendiente) es usar su propia lengua-i (incluyendo crucialmente su propia interfaz léxica) para descubrir esa estructura analizando la señal lingüística. En el caso ideal, la estructura obtenida es idéntica a la que el hablante tenía en mente. Cuando este no es el caso, entonces podemos decir que se ha producido un reanálisis. El reanálisis es, por tanto, un error de descodificación (o de adquisición), y cuando este "error" (esta mutación) se estabiliza en la lengua-i del oyente y se extiende a otros usuarios, entonces decimos que se ha producido un cambio lingüístico. El modelo expuesto predice, en- 
tonces, que los cambios lingüísticos únicamente se producen en las interfaces léxicas que exteriorizan las estructuras sintácticas, y no en el sistema computacional mismo, que permanece invariable. Los cambios lingüísticos, por tanto, no se producen en las lenguas-i globalmente, sino únicamente en las interfaces léxicas de cada una. Así, cuando decimos que una lengua se ha adaptado a tal o cual rasgo social o material del entorno en que se habla, en realidad estaríamos diciendo que alguna dimensión más o menos amplia de la interfaz léxica se ha adaptado, no la lengua-i en su totalidad.

Por otra parte, en el cambio lingüístico, como en el caso de la evolución natural, es imprescindible diferenciar entre las causas por las que surge una innovación y las causas por las que esa innovación se extiende con el tiempo en una población dada. La idea más innovadora y revolucionaria de Darwin (y la más escandalosa en su tiempo) era precisamente esa: que las innovaciones surgen azarosamente y que la selección natural es la fuerza ciega responsable del aparente diseño inteligente de los organismos. Pero si somos conscientes de que esos dos tipos de causas son independientes, entonces la pretensión de que los cambios (tanto en las lenguas como en las especies) están funcionalmente (adaptativamente) motivados se debilita considerablemente.

Puede haber muchos factores que induzcan, por ejemplo, la introducción o la eliminación de un rasgo acústico en un segmento fónico (desde condiciones climáticas hasta la presencia de hablantes de otras lenguas), pero solo se producirá un cambio lingüístico si esa innovación se extiende a otros individuos (a otras lenguas-i). Y esto solo sucederá si los demás hablantes imitan el habla de los innovadores y si dichas innovaciones pasan al habla de otras generaciones. Pero, como ya mostró Labov (1963), el factor crucial en la selección de variantes innovadoras no es la eficiencia funcional o el coste de ejecución, sino el prestigio social de los hablantes que las usan. Algunos autores pretenden que las innovaciones sí tienen motivación funcional (por ejemplo, Croft 2000), pero, como señala Lass (I997: 364) sagazmente, "unless a motivation is arbitrary, its implementation ought not to subject to contingent factors like age, sex, prestige, etc.”. La hipótesis presentada antes de que las innovaciones son procesos accidentales de reanálisis es más coherente con el hecho obvio de que las mutaciones genéticas son procesos accidentales y, desde luego, con el hecho bien conocido por la sociolingüística de que las razones para el éxito de una innovación (mutación) no tienen que ver tanto con su funcionalidad, sino con el prestigio social de quienes las han adquirido accidentalmente.

Hemos visto, pues, que las diferencias entre las lenguas (al igual que las diferencias entre los organismos) son el resultado del cambio. Pero los cambios lingüísti- 
cos únicamente se producen en la dimensión más "superficial" de las lenguas, aquella que está expuesta al aprendizaje a partir del entorno y que es susceptible, por tanto, de reanálisis histórico. De la misma manera, la evolución biológica altera la forma y la estructura de los organismos, pero no modifica la bioquímica con la que se construyen, que ha permanecido inalterada desde la emergencia de las primeras formas de vida.

\section{Tipología estructural de las lenguas y Diversidad CUltural DE LOS HABLANTES}

Incluso aunque admitamos que lo único que cambia históricamente en las lenguas son las pautas de exteriorización, aún se podría argumentar que hay mucho margen para la variación y que, por tanto, la diversidad estructural que observamos en las lenguas podría reflejar procesos de adaptación al entorno. Y, de hecho, sabemos que existe una notable variación en la estructura de las lenguas, por mucho que el modelo presentado en la figura I excluiría el tipo de variación irrestricta que algunos autores (como Evans y Levinson 2009) continúan defendiendo. Sin embargo, la ausencia de correlación entre los diferentes tipos lingüísticos y las diferentes culturas humanas sería un argumento fuerte a favor de una visión restrictiva o débil de la noción de adaptación aplicada a las lenguas.

Los parámetros de variación lingüística estructural que siempre han captado la atención de los tipólogos son aquellos de naturaleza morfosintáctica (esto es, relacionados con cómo la morfología de las lenguas refleja la estructura sintáctica). Hay lenguas con morfemas de marca de caso y lenguas sin ellos, hay lenguas en las que los verbos se conjugan y concuerdan con varios de sus argumentos y lenguas en las que los verbos son invariables, hay lenguas en las que los complementos preceden a sus núcleos y lenguas en las que los siguen, o hay lenguas en las que las palabras interrogativas se mueven al principio de la oración y lenguas en las que permanecen in situ ${ }^{6}$. Entre cada una de las opciones mencionadas hay un abigarrado abanico de estados intermedios. Por ejemplo, entre las lenguas que marcan morfológicamente las relaciones entre predicados y argumentos (bien sea con marcas de caso, con concordancia o con ambos procedimientos), algunas siguen el esquema nominativo-acusativo (agrupando formalmente los sujetos y diferenciando el objeto) y otras el esquema absolutivo-ergativo (agrupando formalmente el sujeto del verbo intransitivo y el objeto y diferenciando el sujeto del verbo transitivo). Y aún hay lenguas que son nominativo-acusativas en ciertos tiempos y/o as-

\footnotetext{
${ }^{6}$ Dryer y Haspelmath (2013) ofrecen una síntesis comprehensiva de la tipología estructural de las lenguas recogiendo mucha información acopiada en los pasados decenios.
} 
pectos y absolutivo-ergativas en otros, o que se muestran de un tipo u otro según si los argumentos son pronombres o sintagmas nominales ( $c f$. Dixon I 994 para una descripción detallada de esta casuística). Toda esa variación es compatible con el modelo presentado en el apartado anterior $y$, de hecho, existen programas de investigación que consideran seriamente la explicación de la variación morfosintáctica en términos de diferencias en el componente de exteriorización (por ejemplo, Richards 2016).

Lo que en el contexto de la presente discusión resulta relevante es que, como ha señalado Pinker (2007), "the non-universal, learned, variable aspects of language don't fit into any meaningful purposive narrative about the surrounding culture”. Las causas de los cambios que producen tal variación estructural son inherentes a la propia estructura lingüística y son el resultado de procesos no teleológicos de reanálisis. Para citar a Pinker de nuevo, esos cambios "aren't part of any symbolic or teleological plan of the culture". Adaptando las palabras de Pinker al ejemplo mencionado, podríamos decir que hay lenguas ergativas y lenguas acusativas, pero no hay culturas ergativas y culturas acusativas. Como sugiere Baker (2003: 350), "indeed, there is no ecological regularity in how the major linguistic types are distributed around the world".

Sin embargo, la asunción de que hay una correlación entre la cultura o la visión del mundo y la estructura gramatical de las lenguas subyace en buena medida a las modernas pretensiones de explicación adaptativa de la diversidad de las lenguas. Nótese que Ladd et al. (201 5: 227) caracterizan esas propuestas como "attempts to relate facts about language structure to facts about speakers and their environment-variables such as group size, geographical location, genetic makeup, and cultural expectations".

En realidad, la tentación de correlacionar la tipología lingüística con la visión del mundo es tan antigua como la propia reflexión sobre la tipología de las lenguas. Ya en el siglo XIX se asumía que el grado de "evolución cultural" determinaba el grado de "evolución lingüística". Así, si volvemos de nuevo al caso de la ergatividad, se afirmaba, por ejemplo, que la ergatividad se correlacionaba con la falta de racionalidad: "What for us is a true cause is for primitive man merely an event involving mystical forces", o "savage man apparently feels that most events are not due to his own volition" (citados por Seely 1977, apud Dixon I 994: 2 I4). Dixon argumenta que, usando el mismo razonamiento y los mismos hechos, también podríamos haber afirmado que solo los hablantes de lenguas ergativas tienen una idea cabal de qué es un agente, dado que son ellos quienes singularizan formalmente el agente. Tras analizar la ergatividad y su distribución en las lenguas del mun- 
do, concluye Dixon que "in fact, there is no one-to-one correspondence between grammatical marking and mental view of the world” (Dixon I 994: 214).

Incluso en tiempos más recientes no faltan propuestas (aunque más sofisticadas) que afirman la existencia de co-variación entre aspectos culturales y gramaticales, como por ejemplo relacionando la complejidad gramatical con la complejidad cultural, tales como las de Swadesh (I97I), Perkins (1988) o Everett (2005). Swadesh (I97I: 49) menciona una correlación entre las categorías flexivas y la extensión social y geográfica de una lengua. Pero dicha correlación, si realmente existe, no revela necesariamente una adaptación de la gramática a la cultura, sino que probablemente sería una consecuencia de la simplificación morfológica, un proceso típico de las llamadas "world languages" (que se discutirá más adelante). Perkins (I988) también propone una correlación entre la complejidad gramatical y la cultural. Revisa en 50 lenguas varios rasgos deícticos morfológicos (tiempo, persona, afijos deícticos), mecanismos sintácticos relacionados con la codificación de la referencia (determinantes, relativos, conjunciones) y los compara usando una medida de la complejidad cultural (basada en el tamaño de las poblaciones, el número de tipos de artesanos o de trabajadores especializados diferentes y la complejidad de las jerarquías sociales y políticas). Perkins encuentra una correlación fuerte que implicaría, en sus términos, un tipo de "linguistic evolution": las lenguas de culturas más complejas tienen menos afijos deícticos y más mecanismos sintácticos. Sin embargo, Nichols (1992) aplica sus métodos a esos datos y señala que esas correlaciones "may actually reflect only accidentally coincident macroareal linguistic distributions and have no ultimate connection to cultural complexity" (ib.: 3 I 7). Por su parte, la célebre y polémica propuesta de Everett (2005) sobre las restricciones culturales en la gramática del pirahã no es estadísticamente significativa y ha sido seriamente cuestionada ( $c f$. Nevins et al. 2009).

Parece, pues, que la conclusión más razonable es que no hay correlación entre la diversidad estructural de las lenguas y la diversidad cultural de sus hablantes. El hecho de que una lengua, por ejemplo el mohaqués, sea más compleja morfológicamente que otra, por ejemplo el inglés, no tiene relación alguna con la complejidad de la cultura en la que esas lenguas se hablan, ni con la sofisticación de su tradición literaria, sino que simplemente depende de una cadena previa de cambios lingüísticos. Los morfemas ligados que caracterizan la morfología compleja de muchas lenguas (como el mohaqués) son con frecuencia el resultado del reanálisis histórico de antiguas palabras libres, mientras que las palabras morfológicamente simples, prácticamente invariables, que caracterizan a otras lenguas (como el inglés) son a menudo el resultado de la pérdida de la complejidad morfológica, también típicamente el resultado de procesos históricos de reanálisis. En ambos casos, los 
reanálisis, como los procesos de mutación genética, son ciegos y azarosos, por lo que las conclusiones de Darwin son claramente aplicables en los dos ámbitos: "There seems to be no more design in the variability of organic beings, and in the action of natural selection, than in the course the wind blows" (Darwin 2000 [I893]: 63).

Tal conclusión tiene de hecho un sólido apoyo empírico. Tanto Nichols (I992) como Nettle (1999) analizan cuantitativamente la diversidad lingüística en el tiempo y en el espacio y, aunque con diferentes muestras y metodologías, alcanzan las mismas conclusiones: aunque pueda haber factores sociales y geográficos que se correlacionan con la diversidad de las lenguas y con la densidad de lenguas, no hay correlación alguna entre la diversidad tipológica estructural y los factores externos. Tal y como señala Nettle (I999: I 37), "structural diversity [...] shows no overall pattern and no correlation with other types of diversity". Es cierto que Nettle sugiere que algunos factores extralingüísticos, tales como el tamaño de la comunidad de hablantes, podrían estar relacionados con la preservación de configuraciones tipológicas menos frecuentes (como por ejemplo el orden OS, en el que el objeto precede al sujeto). Su argumento se basa en la asunción de que los tipos infrecuentes son menos óptimos en términos funcionales, una asunción dudosa, dado que se define la optimidad funcional en relación con la mayor o menor frecuencia de aparición, y no con una métrica independiente (en el apartado 7 se discute con más detalle la compleja relación entre gramática y procesamiento). Si ignoramos ese problema, la sugerencia de Nettle es interesante. La idea central en este caso sería que, al igual que sucede en la genética de poblaciones, los efectos de la deriva azarosa son mayores cuando la población en pequeña. Pero incluso en ese caso no se puede afirmar que haya una correlación entre tipos lingüísticos y factores extralingüísticos, esto es, no se puede afirmar que los grupos pequeños de hablantes favorezcan la evolución de ciertos tipos lingüísticos, ni que haya una relación causal entre los grupos pequeños de hablantes y la posición del sujeto en la oración. Nótese que, de hecho, se podría argumentar más razonablemente que la posible causa del mantenimiento de un tipo infrecuente en un determinado lugar es el aislamiento que caracteriza, por definición, a los grupos pequeños de hablantes, aislamiento que protegería a los hablantes del contacto con hablantes de otras lenguas ${ }^{7}$. Lo que este caso muestra en realidad es que el tamaño de los grupos de hablantes puede influenciar la dinámica de los cambios lingüísticos, algo perfectamente coherente con el modelo general presentado, pero no permite afirmar que un cierto rasgo

\footnotetext{
${ }^{7}$ El orden de palabras es, de hecho, uno de los factores más expuestos a difusión en los casos de contacto de lenguas ( $c f$. Dixon 1997).
} 
estructural (por ejemplo, el orden OS) sea una adaptación a cierto tipo de entorno o contexto lingüístico (por ejemplo, el tamaño de la comunidad de hablantes).

Las conclusiones de Nichols (I992) sobre la evolución histórica de la diversidad lingüística son de plena relevancia en el contexto de nuestra discusión:

This survey has uncovered no evidence that human language in general has changed since the earliest stage recoverable by the method used here. There is simply diversity, distributed geographically. The only thing that has demonstrably changed since the first stage of humanity is the geographical distribution of diversity. (Nichols I992: 277)

Si la generación de la diversidad estructural de las lenguas fuera el resultado de procesos adaptativos a aspectos no lingüísticos (y no una deriva continua dentro de un espacio de diseño restringido) deberíamos esperar hallar algún tipo de progreso o evolución en el cambio histórico de las lenguas, tal y como lo observamos en el desarrollo histórico de otras instituciones culturales (política, arte, ciencia o tecnología), pero no es el caso en absoluto.

Aunque los tipos estructurales de lenguas no se correlacionan con los tipos de sociedades y culturas que pueblan nuestro planeta, aún es posible que sí haya ciertos aspectos formales de las lenguas que puedan ser explicados como procesos de adaptación al entorno por medio del cambio lingüístico. Pero para poder evaluar esta posibilidad, primero tenemos que determinar claramente qué se entiende por entorno y qué aspectos de una lengua pueden ser sensibles al mismo.

\section{5. ¿CUÁL ES EL ENTORNO AL QUE SE PODRÍAN ADAPTAR LAS LENGUAS?}

Hasta ahora he estado asumiendo una noción genérica de 'entorno', tal y como la que se propone, por ejemplo, en el llamamiento al Research Topic de la revista Frontiers in Psychology titulado The adaptive value of languages, en el que se plantea la siguiente propuesta: "to explore the possibility that some aspects of the structure of languages may result from an adaptation to the natural and/or human-made environment". Desde ese punto de vista, la idea de que hay covariación entre la tipología morfosintáctica y aspectos del entorno se puede considerar inadecuada o empíricamente débil. Nótese que el diagrama de la figura I representa una lengua-i cualquiera (esto es, el equivalente de un organismo natural). Tal y como he señalado, cada lengua-i tiene un componente (el componente de exteriorización) que es variable y, por tanto, susceptible de haberse podido adaptar al entorno. Pero entonces la noción de 'entorno' no puede ser la misma que he estado asumiendo hasta ahora, puesto que algunos componentes fijos del lenguaje podrían ellos mismos ser parte del entorno de las partes variables de las lenguas ¿Cuál es, pues, el "medio externo" al que esas partes variables podría haberse adaptado? 
El esquema de la figura I podría interpretarse como una especie de sándwich, de manera que solo las capas "externas" tendrían contacto con el entorno. Así, podría decirse que los componentes CI y SM son, por así decirlo, "más externos" que el sistema computacional, que se encontraría más "encapsulado". Es de esperar que la parte del sistema CI de cada lengua esté en contacto con el resto del sistema conceptual de las personas, de manera que sería esperable que ciertos aspectos del entorno físico, social y cultural en el que se desarrollan y viven las personas podrían tener cierta influencia en el rango de conceptos y nociones disponibles, lo que a su vez explicaría algunas dimensiones relativamente triviales de la adaptación de las lenguas al entorno, tal y como sería el caso del lexicón sustantivo ( $c f$. Regier $e$ a al. 2016). Así, es esperable que en las culturas con una tecnología muy desarrollada haya palabras y frases para denotar instrumentos científicos, técnicas y conceptos no encontrados en lenguas habladas por cazadores-recolectores en las que, por su parte, habrá términos en campos como los relacionados con los frutos salvajes, los animales y el clima desconocidos en las lenguas habladas por comunidades urbanas modernas. Los cambios en la cultura, la tecnología y el estilo de vida a menudo llevan a cambios en el inventario léxico que requerimos para la vida diaria. Cuando una sociedad se mueve de un entorno rural a uno industrializado el repertorio léxico más frecuentemente utilizado cambia. De hecho, algunos estudios cuantitativos del léxico ( $c f$. Ladd et al. 2015) muestran que hay cierta correlación entre, por ejemplo, aspectos ambientales (latitud, radiación ultravioleta, etc.) y el tamańo del repertorio léxico para denotar colores. Pero las diferencias en el tipo y cantidad de elementos conceptuales que tienen expresión léxica específica no están directamente relacionadas con la estructura morfosintáctica de las lenguas. De hecho, las lenguas habladas por sociedades supuestamente más simples a menudo tienen mayor complejidad morfosintáctica (mayor "madurez" en el sentido en el que se emplea el término en Dahl 2004) que la que puedan tener lenguas como el inglés o las lenguas románicas.

En el otro lado del sándwich está el sistema SM, que en las lenguas orales corresponde al sistema vocal-auditivo. Es concebible que ciertos aspectos del entorno físico puedan sesgar los tipos de sonidos más o menos usados en ciertas lenguas ( $c f$., por ejemplo, Everett et al. 20I6), pero de nuevo nos hallaríamos ante efectos muy limitados en la estructura morfosintáctica de las lenguas. Por supuesto que un determinado cambio fonético puede implicar cambios en la morfosintaxis de una lengua, pero no tendría sentido decir que la morfología de la lengua se ha adaptado al nuevo sistema fonológico (y mucho menos al potencial factor externo que indujo el cambio fonético inicial). 
En tal caso, cabe preguntarse qué factores ambientales podrían haber moldeado la deriva histórica de los sistemas morfosintácticos de las lenguas. En mi opinión, es bien posible que tales factores no existan o tengan un efecto relativamente débil, dado que la tipología estructural parece estar relativamente aislada de las dimensiones semántica y material de las lenguas y no parece adaptarse a ellas. Pero si fuéramos a buscarlos, deberíamos buscar primordialmente dentro del cerebro.

\section{El ENTORNo INTERNO AL CEREBRo:}

\section{APRENDIZAJE Y PROCESAMIENTO DEL LENGUAJE}

De acuerdo con el modelo que he descrito en el apartado 3, el objeto de estudio desde una perspectiva cognitiva no son las lenguas entendidas como instituciones sociales, sino las lenguas-i que residen en las mentes/cerebros de los hablantes. Y en este contexto es relevante tener en cuenta que el único entorno con el que los "órganos mentales" están en contacto directo es el cerebro mismo. Si realmente hay un "medio externo" al que las lenguas-i se puedan adaptar, este debe ser interno a la mente/cerebro.

Podría objetarse que la mayoría de los más notables cambios que se han documentado en la historia de las lenguas tienen el contacto con otras lenguas como un factor crucial. Y, en efecto, es claro que el contacto de lenguas tiene mucho más efecto en los fenotipos lingüísticos que el entorno físico o social en el que viven las personas. La ergatividad, por ejemplo, no surgirá porque la gente viva en desiertos o en selvas, pero es probable que surja si los hablantes de una lengua nominativo-acusativa están en estrecho contacto con hablantes de una lengua ergativo-absolutiva. Pero las lenguas no entran en contacto directamente en el entorno físico o en la sociedad, sino únicamente dentro del cerebro de los hablantes. La lengua $A$ solo puede influenciar a la lengua $B$ si algún hablante de $B$ tiene algún tipo de conocimiento de la lengua A. En nuestros términos podríamos decir que el desarrollo de una nueva interfaz léxica puede afectar a la interfaz léxica previamente existente, lo que puede alterar las emisiones lingüísticas que una nueva generación de hablantes empleará para desarrollar su propia interfaz léxica.

Sabemos que la evolución natural solo es posible gracias a la reproducción de los organismos, y sabemos que el cambio lingüístico solo es posible gracias a la transmisión de las lenguas de generación en generación. Buena parte de la estructura de una lengua-i se transmite de padres a hijos junto con el resto de su dotación biológica, pero no es el caso, obviamente, de las partes variables del lenguaje, que se aprenden (se interiorizan) a partir de los estímulos lingüísticos del entorno. En este proceso la tarea del niño que aprende una lengua es la de reproducir en su 
mente/cerebro la interfaz léxica de sus interlocutores, y este es, como la propia duplicación del $\mathrm{ADN}$, un proceso típicamente inseguro - abductivo, como señaló Andersen (1973) - sobre el que descansa el mecanismo del cambio lingüístico. Como ya he señalado, esta es la fase en la que pueden ocurrir mutaciones en la interfaz léxica. Tales mutaciones, dependiendo de su grado de transmisión y extensión, pueden dan lugar a los cambios lingüísticos y, en última instancia, al nacimiento de lo que vemos como una lengua distinta.

Como ha mostrado Dahl (2004) con rigor y detalle, la dinámica habitual del cambio lingüístico produce un incremento natural en la complejidad morfosintáctica de una lengua (lo que el autor denomina "madurez"). Este incremento de complejidad alcanza un límite crítico a partir del cual tiende a mantenerse. El grado de madurez de una lengua se mide en términos de la cantidad de estructuras que implican una historia derivacional previa, esto es, estructuras o construcciones no universales que solo se pueden explicar por medio de largas cadenas evolutivas previas, tales como la morfología derivativa y flexiva, la incorporación, la existencia del tono fonológico, la marcación de caso o la ergatividad. Pero es importante notar ahora que, de acuerdo con el modelo presentado antes, este incremento natural de la complejidad lingüística realmente es un aumento en la complejidad de la interfaz léxica, no en toda la lengua globalmente. En este sentido, no sería adecuado ni riguroso decir que hay lenguas más complejas que otras, sino acaso que hay lenguas con interfaces léxicas más complejas que otras. Y esta es una diferencia crucial. Así, las notables diferencias que hay en términos de complejidad gramatical entre, de una parte, el georgiano y, de otra parte, el tok pisin, no implican realmente diferencias de complejidad en las capas más profundas de estructura lingüística (esencialmente el sistema conceptual-intencional y el sistema computacional), sino más bien diferencias en la evolución histórica de sus componentes de exteriorización. La prueba de ello es que las dos lenguas sirven a sus usuarios para llevar a cabo las mismas funciones cognitivas y comunicativas.

La intuición esencial aquí es simple: a mayor historia previa ininterrumpida de una lengua, mayor complejidad morfosintáctica y viceversa. De hecho, McWhorter (20II) argumenta que el estado natural de una lengua, esto es, cuando no ha habido drásticas interrupciones en su transmisión normal de generación en generación, es "highly complex, to an extent that seems extreme to speakers of languages like English" (McWhorter 20II: I). Parece claro que el cerebro de los niños humanos es capaz de interiorizar interfaces léxicas tan complejas como las de las lenguas nativas americanas o las de las lenguas caucásicas, típicos ejemplos de sistemas maduros (en el sentido de Dahl). Ni los cerebros de otros organismos ni los de la mayoría de los adultos son tan eficientes en la interiorización de sistemas arbitra- 
rios de género y de clasificadores nominales, patrones de concordancia o casos caprichosos, por no mencionar los sistemas fonológicos. En consecuencia, McWhorter postula que cuando encontramos lenguas con muy bajos niveles de complejidad morfosintáctica es lícito sospechar que la acumulación normal de complejidad en tales lenguas se ha visto interrumpida, esto es, que tales lenguas "owe this state to second-language acquisition in the past" (McWhorter 20 I I: 2). Podríamos incluir en esta categoría lenguas como el inglés, las lenguas románicas, el persa, el chino mandarín o el indonesio. Comparadas con otras lenguas relacionadas (como el sánscrito, el latín, el griego clásico o el báltico), estas lenguas se caracterizan por una pérdida de complejidad que revelaría un extendido aprendizaje de las mismas como lenguas segundas (L2) por parte de adultos en el pasado. $\mathrm{Y}$, en efecto, tanto Lupyan y Dale (2010) como Bentz y Winter (2013) presentan evidencia cuantitativa que muestra que las lenguas habladas como L2 por muchos hablantes tienden a tener sistemas de caso nominal relativamente menos complejos que aquellos de las lenguas poco habladas como L2. De acuerdo con este modelo, las lenguas criollas son casos extremos del mismo fenómeno: "where complexity has been lost to a radical degree, we can assume that the language was born in a situation in which adult acquisition was universal" (McWhorter 20 I I: 2). Estos casos de "transmisión subóptima” serían entonces claros ejemplos de cómo los cerebros de los aprendientes adultos han funcionado como un factor ambiental al que ciertas partes de las lenguas se han adaptado.

Otra fuente potencial de influencia modeladora de los sistemas morfosintácticos se podría encontrar en el uso del lenguaje en tiempo real. El modelo que he presentado estipula que solo el componente de exteriorización del lenguaje está sujeto a cambio y, por tanto, a variación. Es esperable, por tanto, que los principios de procesamiento (tanto en la percepción como en la producción del lenguaje) tengan un notable influjo en la estructura y dinámica de los sistemas de exteriorización (esto es, en los mecanismos morfológicos y fonológicos de realización de la sintaxis), precisamente porque estos sistemas son relevantes para el uso del lenguaje para la comunicación. De hecho, sería esperable que los principios de procesamiento del lenguaje ( $c f$. Hawkins 2004 para un modelo explícito y desarrollado) jugaran un papel esencial relacionando entre sí estos dos componentes (esto es, el sistema computacional y la interfaz léxica con el sistema sensorio-motor).

Para examinar de qué manera, y hasta qué punto, podrían funcionar los principios de procesamiento del lenguaje como entornos adaptativos para las lenguas (para su parte variable, según el modelo descrito), podemos considerar la propuesta de Bickel et al. (2015) sobre el desarrollo y persistencia de los sistemas ergativos en relación con una supuesta preferencia universal de procesamiento. Basándose en 
evidencia experimental, Bickel et al. (2015) proponen la existencia de un principio universal que favorece el procesamiento de un SN inicial no marcado (esto es, en nominativo o en absolutivo) como un agente. Cuando el resto de la oración muestra que ese $\mathrm{SN}$ no marcado no es un sujeto agentivo (como sería el caso en las lenguas ergativas que marcan específicamente los sujetos agentivos de los verbos transitivos), se observa en sus experimentos un potencial evocado $(\mathrm{N}-400)$ que parece señalar el reanálisis del papel semántico del primer $\mathrm{SN}$ (por ejemplo, como un argumento paciente o tema). Bickel $e t$ al. plantean que este principio es "species-wide and independent of the structural affordances of specific languages" (ib.: 2) y que, como tal, "the principle favors the development and maintenance of case-marking systems that equate base-form cases with agents rather than with patients" (ib.: 2), esto es, favorece los sistemas nominativo-acusativos sobre los sistemas absolutivo-ergativos. Basándose en una amplia base de datos de cambios lingüísticos en diferentes familias de lenguas (6 I 7 lenguas en total) observan los autores que de las dos posibles direcciones de cambio lingüístico (ergativo $>$ acusativo o acusativo > ergativo) las lenguas muestran un claro sesgo hacia el primero de ellos:

Languages tend to avoid ergatives when they evolve over time: if a language has ergative case marking, it is more likely to lose than to keep it, and if a language lacks ergative case marking, it is unlikely to develop it. To be sure, ergative cases can arise and be maintained for a while, but the probabilities of this are always lower than the probabilities of avoiding ergatives. (Bickel $e t$ al. 2015: I8)

Si las conclusiones de Bickel et al. son correctas, estaríamos de nuevo ante un caso claro de cómo un factor externo a la lengua (pero interno a la mente) puede condicionar la evolución de las lenguas en el proceso de cambio. Pero los hechos observados también nos llevan a una importante conclusión en lo referente al grado de adaptación de las lenguas al entorno: incluso aunque un principio de procesamiento general ejerza una presión detectable sobre los sistemas lingüísticos, la inercia de la historia previa de una lengua es capaz de sobreponerse a esas fuerzas, mostrando que la estructura morfosintáctica es obstinadamente resistente a las presiones adaptativas externas, incluso aunque sean internas a la mente/cerebro y supuestamente universales.

También es muy importante tener en cuenta que los sistemas ergativos son sistemas maduros (en el sentido de Dahl), algo que podría explicar, al menos en parte, tanto la desigual distribución estadística de los dos tipos de lenguas (a favor de las nominativas) como el sesgo en la evolución señalado por Bickel et al.

Y también es importante señalar el hecho de que lenguas como el vasco, que son plenamente ergativas (a diferencia del hindi, lengua con la que experimentan Bickel et al.), no muestran síntomas de desajuste y son plenamente funcionales 
para sus usuarios. Además, el mero hecho de que hayan existido y existan procesos de desarrollo histórico de la ergatividad (de lo contrario no existirían lenguas ergativas) muestra claramente que la estructura gramatical es en buena medida inmune a la influencia de factores externos (esto es, no gramaticales). Y, en efecto, una síntesis reciente de la investigación sobre los costos de procesamiento en vasco (Zawiszewski 2017) concluye que no hay diferencias profundas en los mecanismos de procesamiento de lenguas con diferentes sistemas de marca de caso:

In general, the electrophysiological pattern found when processing ergative case violations corresponds to that revealed during similar case violations in accusative languages [...] and thus indicate that the mechanisms underlying language comprehension are comparable across languages with a different case morphology. (Zawiszewski 20I7: 706)

\section{LO POSIBLE Y LO PROBABLE: GRAMÁTICA, TIPOLOGÍA E HISTORIA}

Como hemos visto, para los autores de corrientes funcionalistas la explicación de la tipología estructural de las lenguas es, en términos generales, el resultado de la adaptación de las lenguas a aspectos externos a la propia gramática ( $c f$. ., por ejemplo, Haspelmath 2008). El punto de vista que he planteado en esta aportación confía mucho más en la inercia o deriva interna de los cambios lingüísticos en términos de reanálisis como la base de nuestra comprensión de la agrupación sistemática de propiedades morfosintácticas de las lenguas. La idea esencial sería entonces que la tipología lingüística que observamos reflejaría la dinámica interna de los efectos de los cambios lingüísticos en las interfaces léxicas, y no la adaptación de las lenguas a diferentes entornos.

Si ampliamos la perspectiva de nuestra mirada e intentamos abarcar la visión de las ciencias evolutivas, observaremos que este contraste entronca con la controversia análoga en la teoría evolutiva moderna sobre las fuentes de la estructura de los organismos vivos, tal y como he señalado en el apartado 2 al mencionar la caracterización de la misma hecha por Gould. De hecho, el gran evolucionista George Williams (1992) planteaba que la visión anti-neodarwinista, con su confianza en las leyes generales de la naturaleza para condicionar y hasta determinar la estructura de los seres vivos, sostendría una concepción del organismo-como-un-cristal, mientras que la visión neodarwinista, con su confianza en la adaptación, sostendría una concepción del organismo-como-un-artefacto: "Mechanistic biologists assume an organism-as-crystal and adaptationists an organism-as-artifact concept" (Williams I992: 6). Pero añade además una tercera concepción del organismo, la del organismo-como-documento: "An organism-as-document approach should also be recognized for biologists interested mainly in unique evolutionary histories" (Williams I992: 6). La visión del organismo como un documento no es incompatible con 
ninguna de las otras dos y tiene que ver con la naturaleza histórica de los seres vivos. Así, el propio Williams recuerda precisamente que con frecuencia muchos rasgos de los seres vivos no son especialmente funcionales e incluso no son adaptativos. Menciona concretamente el hecho de que todos los vertebrados estén expuestos al ahogamiento por el hecho de que los sistemas respiratorio y digestivo se cruzan en la garganta (un rasgo acentuado especialmente en los humanos adultos por la aparente adaptación para el lenguaje representada por el descenso de la laringe). Dicha propiedad solo tiene sentido desde el punto de vista del organismo como un documento, esto es, como un legado histórico recogido por el organismo como herencia de un antepasado en el que la parte anterior del tracto alimenticio se modificó para formar un sistema respiratorio antes innecesario.

En este contexto, parece claro que la concepción chomskiana, especialmente la minimalista, se decantaría más por una visión de las lenguas análoga a la del cristal, mientras que la aproximación funcionalista se decantaría por una visión basada en el modelo del artefacto. Y, en efecto, las lenguas revelan en su estructura aspectos de elegancia formal (tal y como pone de manifiesto la investigación minimalista) y aspectos de eficiencia funcional (tal y como pone de manifiesto el hecho obvio de que son utilizables para el pensamiento y la comunicación), pero mi argumento es que no existen pruebas para afirmar que esos aspectos se manifiestan más o menos intensamente en unas lenguas que en otras, o en algunos tipos lingüísticos que en otros. Si esto es así, entonces los aspectos formales y funcionales son propios de lo que es común a las lenguas, precisamente porque son los que han moldeado evolutivamente la llamada Gramática Universal (GU), la arquitectura común a todas las lenguas humanas. Las partes variables, por tanto, son reflejo de la naturaleza esencialmente histórica de la interfaz léxica incluida en nuestros órganos del lenguaje.

Sin embargo, también hay voces desde el punto de vista formalista que abogan por la hipótesis de que la propia teoría gramatical no tiene relevancia para explicar la tipología, como es el caso de Newmeyer, que dedica una monografía entera (Newmeyer 2005) a intentar demostrar que la teoría gramatical no puede explicar la tipología estructural de las lenguas. En su afortunada expresión, la gramática tiene que explicar lo posible, pero no lo probable. Lo que esto significa es que la teoría gramatical debe determinar qué lenguas son posibles e imposibles, pero no puede explicar por qué ciertos tipos de lenguas son más probables que otros, esto es, por qué ciertas configuraciones de propiedades son más frecuentes que otras, por qué existen, en definitiva, los tipos lingüísticos. Creo que Newmeyer tiene razón en general, pero de acuerdo con la argumentación anterior, no parece que se pueda afirmar que la explicación de los tipos lingüísticos sea del todo ajena a la 
llamada teoría gramatical y se deba seguir enteramente de la adaptación a aspectos extragramaticales, como sugiere el autor.

Para aclarar esto, pongamos por caso que asumimos el parámetro clásico de la dirección del núcleo (según el cual las lenguas deben elegir si el núcleo de un sintagma va a la izquierda o a la derecha de su complemento) y supongamos que descubrimos que la mayoría de las lenguas son consistentes en la dirección del núcleo en las diversas categorías (bien sea VO, P-SN, Aux-SV, etc., bien sea OV, SN-P, SV-Aux, etc.) mientras que solo una minoría son inconsistentes (VO, pero SN-P, etc.). En este sentido, una lengua inconsistente sería menos probable que una consistente (como parece ser el caso, de hecho). La explicación de este dato podría tomar tres caminos:

(I) Hay una explicación gramatical que predice ese hecho.

(2) Hay una explicación funcional/adaptativa que predice ese hecho.

(3) Es un suceso contingente desde el punto de vista de la forma y de la función.

En principio es poco probable que la explicación de la línea de (3) sea satisfactoria como primera opción, pero no es teóricamente imposible. Por ejemplo, pudiera ser el caso de que simplemente las lenguas que llamamos "inconsistentes" hubieran tenido menos "suerte" como consecuencia de la evolución histórica de los pueblos que las hablan. Sería precipitado confiar en ese tipo de explicación e ignorar las otras, pero hay ocasiones en las que, de hecho, las respuestas del tipo de (3) son las más adecuadas, como cuando la causa de que un tipo de lengua sea más frecuente en un área determinada es el resultado de una división de una protolengua en numerosas lenguas y la extinción a su costa de otras. Para hacernos una idea de la importancia de (3) imaginemos, por ejemplo, que en lugar de contar lenguas contamos hablantes y que nos centramos solo en las lenguas más frecuentes respecto del orden básico de palabras (SVO y SOV). Aunque aceptemos que en el mundo existen más o menos el mismo número de lenguas del tipo SVO que del tipo SOV (como parece ser el caso) en seguida descubriríamos que hay muchas más personas en el mundo que hablan lenguas del tipo SVO que del tipo SOV (ya que las tres lenguas más habladas en el mundo - el chino mandarín, el inglés y el español- tienen básicamente ese orden). Está claro que la explicación de por qué hay más seres humanos que hablan lenguas SVO que lenguas SOV (o de cualquier otro tipo) no es ni puramente gramatical ni adaptativa, sino totalmente ajena a la estructura de la mente humana, pues dependerá de las migraciones, del éxito de los imperios, del armamento, de los recursos materiales, etc. (esto es, de las razones por 
las que hay más personas en el mundo actual que hablan inglés, chino y español que vasco o japonés).

Por supuesto, Newmeyer no está proponiendo que la teoría gramatical no deba predecir por qué hay más personas que hablan lenguas de un tipo u otro (pues es algo que nadie defiende), sino que se refiere a que la tipología lingüística solo responde a la explicación de (2), esto es, a que la explicación de las agrupaciones tipológicas estructurales y su distribución no es asunto de la teoría gramatical, sino que debe estar basada en el uso del lenguaje y, más concretamente, en el procesamiento. Ya hemos visto en el apartado anterior que esta conclusión no es tan fácil de obtener como puede parecer a primera vista.

En mi opinión, no obstante, la argumentación global de Newmeyer es defectuosa porque confunde la GU (o una teoría específica sobre la GU) con la propia teoría gramatical. Así, en la introducción de su libro dice que pretende criticar la idea de que "anything internal to Universal Grammar predicts why some morphosyntactic features are more common crosslinguistically than other", para concluir que "Universal Grammar predicts the set of possible languages, not the set of probable languages" (Newmeyer 2005: ix $)^{8}$. Pero en realidad esto es un ataque a un hombre de paja, pues la moderna teoría paramétrica no pretende eso. Si su propuesta se quedara ahí, a Newmeyer le hubieran sobrado 277 de las 278 páginas de su libro (bibliografía incluida). Sin embargo, su propuesta va más allá. Lo que argumenta detalladamente en realidad es que tampoco la propia teoría gramatical (formalista) es relevante para la tipología: "It is not the task of formal grammar to account for the typological variation that we find across languages" (Newmeyer 2005: I 19). Pero nótese que se trata de dos propuestas distintas. Por supuesto que las dos son teóricamente posibles, pero no es cierto que los argumentos que apoyan la primera se puedan emplear como argumentos que también apoyen la segunda. Sin embargo, esa es la estrategia de Newmeyer. Así, la prueba esencial que ofrece Newmeyer para sustentar su hipótesis de que la teoría gramatical no es relevante para la tipología lingüística es que los factores que determinarían por qué hay ciertas correlaciones entre los tipos de reglas que escogen las lenguas no tiene nada que ver con el contenido de las propias reglas, sino que derivan del uso de los sistemas completos. Pero cabe señalar que incluso en el caso de que los factores derivados del procesamiento tuvieran una clara influencia en la distribución estadística de las variables entre las lenguas (un asunto plenamente empírico), en modo alguno se

\footnotetext{
${ }^{8}$ En el inicio del capítulo central de su libro aún es más rotundo: "My goal in this chapter is to launch a frontal assault not just on the parametric approach to grammar, but also on the very idea that it is the job of Univeral Grammar per se to account for typological generalizations" (Newmeyer 2005: 73).
} 
sostendría la afirmación de que la teoría gramatical no es parte central de la explicación de la tipología estructural de las lenguas.

Una nueva analogía con la evolución natural nos servirá para aclarar este punto. Asumamos que la GU es el equivalente de la biología molecular, que la teoría gramatical es el equivalente de la genética y que los factores externos son el equivalente de la selección natural. Es bien cierto que Darwin sabía poco de biología molecular y de genética (no por desinterés, sino por imposibilidad cronológica), lo que no le impidió dar una explicación relevante de la diversidad de las especies. Pero sería sumamente arriesgado afirmar que ni la biología molecular ni la genética están en la base de la explicación de cómo es posible que la selección natural funcione y en la de qué tipos de organismos pueblan la tierra. Es cierto también que la biología molecular no puede predecir qué especies existirán o no existirán, ni qué especies serán más frecuentes que otras. Al fin y al cabo, desde el punto de vista bioquímico no existen las especies naturales. Pero eso no es todo lo que afirma Newmeyer. Como identifica la GU con la teoría gramatical, lo que estaría afirmando es que tampoco la genética tiene nada que ver con la explicación de la diversidad de las especies y su distribución, y eso sí es claramente inadecuado.

Quizá otro Gedankenexperiment, algo disparatado, pueda ayudar a aclarar este punto. Imaginemos que situamos en un entorno natural semejante a la sabana africana que vio nacer a nuestra especie una colonia de hormigas y una colonia de chimpancés y mantenemos la situación durante varios millones de años: ¡cuál de las dos colonias tendría más posibilidades de producir una repetición del proceso que dio lugar al Homo sapiens? Aunque en ambos casos las probabilidades sean remotas, parece claro que el segundo grupo estaría en mejor disposición. Pero nótese que en este caso la selección natural (representada por el entorno) y la biología molecular son las mismas. Lo único que podría explicar que el grupo de chimpancés fuera a tener más probabilidad de engendrar un linaje humano sería el hecho de que estos últimos ya estarían más cerca del resultado que las hormigas. $\mathrm{O}$, en otras palabras, que el número de mutaciones genéticas que deberían producirse para derivar un ser humano de una hormiga sería mucho mayor que el necesario para hacerlo a partir de otro primate.

En el modelo que he propuesto en la sección 3, la tipología estructural de las lenguas depende de la configuración específica de sus interfaces léxicas (que serían el equivalente del genoma de cada lengua), luego la explicación última de la tipología estructural de las lenguas (esto es, de por qué ciertos rasgos tienden a agruparse) no estará en la GU (la "biología molecular"), que se limita a establecer lo posible y lo imposible (al igual que la bioquímica del ADN determina las formas de vida posibles e imposibles), ni en la adaptación al entorno (la selección natural, que 
selecciona las variantes más aptas dado un entorno concreto), sino en la historia gramatical (esto es, en los "genomas" que recogen todas las variantes seleccionadas en el pasado).

Por supuesto, no es inconcebible que haya factores extragramaticales que expliquen la difusión de ciertas variantes, pero en cualquier caso no serán los factores extragramaticales los que exclusivamente determinen los cauces de variación en la estructura gramatical, pues esta dependerá crucialmente de las agrupaciones puramente gramaticales, esto es, estará constreñida por los sucesos del pasado. En el modelo que he sugerido, los parámetros de variación (esto es, las correlaciones tipológicas) tienen que ver con los caminos que se abren o se cierran al ir fijando ciertas propiedades fenotípicas. En el ejemplo que acabo de plantear, es muy poco probable que una estirpe de hormigas siga (en, digamos, el próximo millón de años) un camino evolutivo que dé lugar a una especie análoga cognitivamente al ser humano. Pero eso es improbable no solo por factores externos o ambientales, sino crucialmente porque el genoma que instruye el desarrollo de una hormiga va "tomando decisiones" que cada vez hacen menos probables la serie de cambios que darían lugar a una hormiga con I 500 centímetros cúbicos de encéfalo. La concepción de los tradicionales parámetros como nichos jerárquicos de propiedades gramaticales vinculadas refleja, sin asumir diferencias de marcación ni beneficios de procesamiento o funcionales, cómo ciertas soluciones se van haciendo más o menos probables, o imposibles, conforme se desarrolla el objeto en cuestión.

De manera interesante en este contexto, Harris (2008) ha mostrado, basándose en ciertas lenguas del Cáucaso, que la explicación de la existencia de estructuras tipológicas poco frecuentes o raras puede ser simplemente histórica, en el sentido de que dichas estructuras dependerán de la concurrencia de determinados cambios históricos en la gramática de las lenguas. En general, como observa la autora, "the more changes are involved, the less likely all will happen to co-occur" (Harris 2008: 76) ${ }^{9}$. En este contexto, la siguiente afirmación de Newmeyer (2005: 75), que resume el núcleo de su tesis, resulta inaceptable, por demasiado simple: "The degree of grammatical variation is in fact highly constrained, but much more by performance factors than by UG”. Eso sería tanto como decir que los únicos límites a las formas de vida existentes son la biología molecular y la selección natural (como en la segunda opción del texto de Gould citado antes). Por supuesto que son límites, pero no los

\footnotetext{
${ }^{9}$ Así, concluye: "It is the fact that so many specific factors or changes must co-occur or occur sequentially in an appropriate order that explains the infrequency of these constructions, and no further explanation is needed. Many typological unusual constructions can be explained as uncommon combinations of common changes. In this sense, they are the result of historical accident" (Harris 2008: 76).
} 
únicos, ni probablemente los más interesantes en ciertos niveles. Este punto de vista simplemente ignora la noción del "organismo como documento".

La pretensión de que solo los factores de procesamiento (según el modelo de Hawkins) son responsables de las agrupaciones tipológicas choca directamente no solo con la teoría paramétrica clásica (como argumenta detalladamente Newmeyer), sino también con los desarrollos posteriores de la misma. En el modelo que he propuesto, los factores de procesamiento, en la medida en que determinen el uso de las construcciones gramaticales en ciertos contextos, podrían tener una influencia en la explicación de la distribución de ciertas configuraciones tipológicas (fundamentalmente en el proceso de cambio histórico), pero el planteamiento básico es que la fuente de la variación estructural entre las lenguas está en la interfaz léxica. De esto se sigue que un factor fundamental en la determinación del tipo lingüístico de una lengua dada sea la historia, esto es, los diversos procesos de cambio lingüístico que dan lugar a la variación en la determinación de la estructura de los sistemas de interfaz.

Consideremos un ejemplo concreto de los que discute Newmeyer para aclarar este punto. Como el propio autor señala, una correlación interlingüística muy robusta es que en las lenguas con orden $\mathrm{VO}$ es mucho más frecuente que las palabras interrogativas (como quién, qué, cuánto, etc.) se muevan al principio (como en español), mientras que en las lenguas con orden $\mathrm{OV}$ es mucho más frecuente que las palabras interrogativas se queden in situ (como en japonés). Una propuesta de explicación gramatical de ese hecho es la de Kayne (1994). Kayne propuso que todas las lenguas son subyacentemente Especificador-Núcleo-Complemento, lo que predice un orden SVO. Una manera de justificar la existencia de lenguas SOV es estipular un movimiento de parte de la estructura flexiva al especificador del complementante ( $c f$. Kayne I994 para los detalles, ahora irrelevantes). Si el especificador del complementante está ocupado, entonces se explicaría por qué en las lenguas del tipo $\mathrm{OV}$ es mucho menos frecuente el movimiento al inicio de las palabras interrogativas. La objeción que ofrece Newmeyer (2005: 106) a esta explicación no se basa en rechazar algún supuesto o en denunciar un mal análisis, como sería esperable, sino en negar la hipótesis de partida por el hecho de que la teoría de la asimetría de Kayne predice que debería haber muchas más lenguas del tipo SVO que del tipo SOV, lo que ciertamente no es el caso. Pero al margen ahora de si Kayne tiene razón o no (su análisis es sin duda complejo y controvertido), lo relevante es que Newmeyer rechaza la hipótesis ignorando la gramática. De alguna manera Newmeyer está dando a entender que la historia gramatical no cuenta y está ignorando las causas por las que una lengua puede ser OV. Si, como sugiere Kayne, el orden $\mathrm{OV}$ es derivado por ciertos movimientos y si, en efecto, las lenguas 
OV son típicamente más complejas morfológicamente, entonces no hay razón para exigir la predicción de que una lengua $\mathrm{VO}$ tiene que ser más probable: lo que se predice, correctamente, es que entre las lenguas VO, las que tengan, por ejemplo, concordancia de objeto, serán minoría, lo que también es el caso. En otras palabras, lo que la hipótesis de la asimetría predice, al establecer una correlación motivada entre la morfología flexiva y el orden de palabras, es que ciertas propiedades gramaticales en ciertos tipos de lenguas serán más probables que otras. Pero la explicación es gramatical, aunque pueda concurrir, en un momento u otro del proceso, el efecto del uso del lenguaje y del procesamiento.

Por su parte, como antes he señalado, la apelación al procesamiento y en general a factores externos de uso para explicar las correlaciones tipológicas tiene un problema esencial, y es que los sistemas de procesamiento son los mismos independientemente de la gramática de cada lengua. Pero si los sistemas de procesamiento son los mismos, ejercerán la misma presión en todos los seres humanos, lo que predice uniformidad tipológica. Para escapar de esta conclusión, que es empíricamente incorrecta, los autores funcionalistas suelen recurrir al modelo de las presiones en conflicto, de manera que la variación observada se justifica porque algunas lenguas han cedido más a unas presiones que otras, que a su vez se han visto sometidas a mayor presión de otro tipo ${ }^{10}$. La falsabilidad de estas just-so-stories es muy discutible y recuerda a muchos pasajes análogos en el discurso panadaptacionista neodarwinista, que por ello Gould y Lewontin (1979) calificaron de panglossiano. De hecho, el modelo de Newmeyer predice que lo más probable (esto es, lo más frecuente) es lo que mejor se procesa, pero, como antes señalaba, siempre cabe la duda de si no habremos decidido qué es lo que mejor se procesa a partir de lo que es más probable. No es mi intención negar que las presiones funcionales puedan tener un efecto en los sistemas gramaticales, pero el mero hecho de que el efecto sea diferencial es una prueba de que la estructura gramatical ya determina qué presiones pueden o no pueden afectar a qué partes del sistema, con lo que la exclusión de los factores puramente gramaticales resulta claramente precipitada.

Por otra parte, no siempre es tan fácil como sus proponentes dan a entender distinguir los principios del procesamiento de los principios gramaticales ${ }^{11}$. De hecho, no es costumbre de estos autores (por ejemplo, el mencionado Hawkins

\footnotetext{
10 "The idea that cross-linguistic differences are due to different weightings of conflicting forces has been present in the functionalist literature for a long time" (Haspelmath 2008: 8I). Véase precisamente Newmeyer I 998 : I37 ss. para un ataque a ese modelo de explicación. En otra obra posterior afirma: "Since for any functional factor there exists another factor whose operation would lead to the opposite consequence, the claim that some particular functional factor 'explains' some particular instance of language change has the danger of being empty" (Newmeyer 2003: 32-33).

${ }^{11}$ Como seńala un revisor anónimo, autores como O'Grady (2005) plantean directamente que no hay diferencia entre la gramática y los sistemas de procesamiento del lenguaje.
} 
2004) considerar cómo evolucionaron los procesadores en la especie, qué grado de variación cultural tienen, cómo y con qué tipo de estímulo se desarrollan en el individuo y de qué manera actúan en otras tareas cognitivas ${ }^{12}$. Por ejemplo, el principio de Hawkins discutido por Newmeyer (2005: I23-I 24) según el cual las gramáticas están diseñadas para reducir el tiempo de reconocimiento de los constituyentes (que le sirve para explicar la relativa frecuencia de la consistencia en la dirección del núcleo) ciertamente podría concebirse como no gramatical, sino como una presión en las gramáticas (aunque habría que demostrar que actúa fuera del procesamiento del lenguaje), pero en todo caso el sistema opera sobre representaciones gramaticales, y estas son sistemas complejos con muchas más propiedades que las potencialmente visibles para los procesadores.

Según Newmeyer (2005: I I9) no tenemos más razones para pensar que la GU deba explicar por qué hay más lenguas $\mathrm{VO}$ que OV que para explicar por qué algunas lenguas tienen más expresiones honoríficas que otras o más préstamos léxicos que otras. Es fácil estar de acuerdo en eso (ya que si hay lenguas OV y VO está claro que la GU no determina ese rasgo). Pero en modo alguno se puede aceptar que se traten los tres asuntos del mismo modo. Desde un punto de vista tipológico los tres factores podrían tener un mismo tratamiento estadístico, y los tres pueden estar expuestos en su variación a fenómenos externos comunes, tales como la difusión zonal de rasgos, las migraciones, etc. Lo que no parece admisible es que el primer tipo de variación se trate como los otras dos en todos los sentidos, como si los tres fueran ajenos a la gramática en la misma medida. En otras palabras, es posible que la GU no tenga nada que decir sobre la mayor o menor frecuencia de las lenguas VO frente a OV, pero sí en la determinación de la propia ontología de la variante, a diferencia quizá de los otros dos casos.

Siguiendo la estrategia expositiva de Newmeyer se podría resumir de la siguiente manera la perspectiva que parece más adecuada según el modelo aquí expuesto:

— La GU determina lo posible.

— Lo probable está determinado por la historia.

- La historia está constreñida por:

- contingencias históricas, "cuellos de botella", etc.;

- procesamiento y otros factores funcionales;

\footnotetext{
${ }^{12}$ Hay muchas preguntas que a menudo no se hacen en este tipo de aproximación: ¿el procesador es idéntico para todas las lenguas?, ¿se desarrolla en relación con el entorno o de manera totalmente independiente?, ¿el procesador es lingüístico o sirve para otros tipos de estímulos?, ¿emplea en esos casos los mismos principios?, ¿cómo se conecta el procesador con las entidades lingüísticas?, ¿qué tipo de entidades o constituyentes reconoce el procesador?, etcétera.
} 
- la propia GU como conjunto de requisitos de funcionamiento del sistema que vincula el LIP y la interfaz léxica de cada lengua.

- Luego lo probable no es sólo una cuestión de adaptación de las lenguas al procesamiento en tiempo real.

Consideremos, por ejemplo, el parámetro polisintético de Baker (I 996). Incluso en el caso de que aceptáramos al modo clásico que realmente existe un principio de la GU que especifica dos posibles valores (esto es, si cada argumento del verbo tiene que estar marcado pronominalmente en el verbo o no), es evidente que la selección positiva del parámetro exigirá que la lengua del entorno disponga de afijos pronominales que se adjunten al verbo, de morfemas de concordancia, o al menos de elementos susceptibles de ser reanalizados como tales. Esto es, para que una lengua sea tipológicamente polisintética, antes han debido acontecer procesos históricos específicos en la morfología de la lengua, y si estos no han sucedido, la adopción de un determinado tipo es imposible o altamente improbable. La teoría gramatical tiene que describir y predecir las correlaciones relevantes, pero obviamente no tiene que predecir si habrá muchas o pocas lenguas polisintéticas, que será algo que dependerá de factores externos (no ya a la gramática, sino a la propia mente).

Ahora bien, el hecho de que haya lenguas que habiendo evolucionado independientemente durante miles (o decenas de miles) de años acaben teniendo una estructura muy similar es muy significativo. Por decirlo así, demuestra que hay muchas menos estructuras posibles que lenguas. Nótese que eso no sucede en el léxico. Lo esperable de lenguas que han evolucionado independientemente es que tengan léxicos muy diferentes ${ }^{13}$. Si todas las partes de una lengua evolucionaran de la misma manera, entonces deberíamos esperar que al igual que ciertos elementos léxicos adquieren sus significados gradualmente y se van adaptando a la cultura que las usa, también las estructuras gramaticales deberían hacerlo, pero no es así en absoluto. Si algunos aspectos del léxico y la fraseología se comportan como bolas de billar, la estructura gramatical se comporta como los poliedros de Galton.

Es en ese sentido en el que se puede afirmar que la historia está constreñida por la GU, no porque lo esté directamente, sino porque las condiciones que impone la GU para que se construya una lengua-i y las propiedades concretas de los distintos componentes de la lengua-i restringen drásticamente las direcciones del cambio lingüístico estructural. Una conclusión similar alcanza Kiparsky (2008), quien

\footnotetext{
${ }^{13}$ Como señala Baker (200I: I I 5 ) es muy poco probable que un diccionario mohaqués-inglés nos pueda servir también como diccionario del mayalí-inglés, pero una gramática del mohaqués puede servir como una buena aproximación inicial a la gramática del mayalí, aunque no tanto del inglés.
} 
plantea que frente al programa de investigación que busca las causas de las generalizaciones tipológicas en procesos históricos recurrentes, se debe situar también el programa estructuralista de buscar en la otra dirección: que la manera en que las lenguas cambian depende de las propiedades estructurales. Enmarcada en ese programa es en el que resulta relevante la propuesta sobre el papel de la historia en la determinación de lo probable de Longobardi (2003). Así, según este autor, si la respuesta a la pregunta ¿Qué son las lenguas actuales? se incardinaría en lo que Chomsky denomina la adecuación descriptiva y la respuesta a la pregunta ¿Cuáles son las lenguas biológicamente posibles? se relacionaría con lo que Chomsky denomina adecuación explicativa, la pregunta ¿Por qué tenemos precisamente las lenguas actuales y no otras? dependería de la adecuación histórica, que para este autor está un peldaño por encima de la anterior (y solo un peldaño por debajo de la adecuación evolutiva, que sería la necesaria para responder a la pregunta de por qué tenemos las lenguas biológicamente posibles y no otras). Que la explicación de por qué (dentro de las posibles) existen las lenguas que existen y no otras sea histórica no se puede realmente poner en duda. La hipótesis de que la historia está formalmente restringida (según un modelo anti-neodarwinista) es la que convierte a la teoría paramétrica en una fuente insoslayable de adecuación tipológica de la teoría gramatical. En este sentido se podría decir que la adecuación histórica y la adecuación tipológica son dos caras de la misma moneda.

En el modelo que he expuesto, los estímulos externos restringen drásticamente las diversas opciones para el desarrollo de la interfaz léxica de cada lengua-i, esto es, acotan aún más el espacio de diseño, dando la sensación de que estos espacios están de alguna manera constreñidos externamente. Pero esta es una falsa sensación. La hipótesis más razonable es que el desarrollo de una lengua-i (de la FL de una persona) está siempre doblemente constreńido: primero, por la propia GU biológicamente determinada, lo que incluye no solo el sistema computacional, sino también la naturaleza de los sistemas cognitivos, perceptivos y motores que interactúan para formar el sistema de conocimiento que llamamos lengua-i; segundo, porque quien aprende una lengua debe memorizar una interfaz léxica y emparejar significados y sonidos de acuerdo con restricciones propias de esos sistemas y en función de la cultura ambiental (los estímulos lingüísticos de cada lengua-i, portadores del legado histórico). En este caso tiene razón Longobardi (2003) al situar la adecuación histórica de la teoría gramatical en tan alto nivel. Algunos modelos paramétricos (por ejemplo, Roberts y Roussou 2003) proponen que la tipología estructural se sigue en buena medida de la presencia o ausencia de ciertos rasgos asociados a determinadas categorías funcionales. En la medida en que esta caracterización funcione bien empíricamente, se debe considerar descriptivamente adecuada, pero la 
adecuación explicativa más profunda vendrá de la explicación histórica en cada caso particular de los sucesos previos relevantes para la presencia o ausencia de dichas configuraciones de rasgos en las lenguas. Aunque quizá Longobardi incurra en el error de ignorar la relevancia del proceso de adquisición (en el sentido de que la historia de los sistemas lingüísticos está determinada crucialmente por los procesos restringidos y selectivos de adquisición del lenguaje), es indudable que la explicación de la tipología no puede desvincularse de la historia de las lenguas, lo que no implica que tengamos que hacer una interpretación adaptativa.

\section{Conclusiones}

Si adoptáramos la sugerente visión de McWhorter (20I I), podríamos decir que los cerebros de los adultos han influenciado el desarrollo histórico de algunas lenguas de manera decisiva. Desde un punto de vista externista, podríamos incluso concluir que algunas lenguas se han adaptado a los poco flexibles cerebros maduros simplificando sus complejidades morfológicas históricas y haciéndose más fáciles de aprender. Pero desde el punto de vista internista defendido aquí, dicha conclusión es inadmisible, porque las lenguas no son únicamente objetos culturales que se transmiten de cerebro en cerebro. En cierto modo sería lo mismo que decir que la piel del tigre tiene la forma que tiene porque ha evolucionado para adaptarse a la forma del cuerpo del tigre, mientras que la piel del caballo se ha adaptado al cuerpo del caballo. Nótese que esa afirmación, aparentemente impecable, oculta que la piel del tigre (o la del caballo) no es un parásito o un organismo que se añade al animal, sino que es una parte del cuerpo del tigre y que, por tanto, sería absurdo y poco informativo plantear su evolución como una historia de adaptación a los cuerpos desnudos de los animales en cuestión, por mucho que, en efecto, las pieles de esos animales tengan rasgos claramente adaptativos respecto del entorno externo.

La aproximación que he llamado externista, basada en última instancia en la concepción de las lenguas como productos culturales, tiende a identificar las lenguas con las interfaces léxicas. Esta identificación, al menos en parte, está detrás de las diferentes maneras de apreciar el grado de adaptación de las lenguas al entorno que hemos observado en esta aportación. Desde el punto de vista internista, en el que las lenguas son sistemas cognitivos con diferentes pautas de exteriorización, la noción de adaptación de las lenguas al entorno extralingüístico solo es aceptable en un sentido débil, esto es, relacionado con aspectos relativamente superficiales de la estructura de las lenguas humanas. En modo alguno he pretendido en esta aportación concluir que afirmaciones como la siguiente sean incorrectas o que no reflejen aspectos interesantes y dignos de investigación: 
[...] linguistic differences, from sounds to grammars, may also reflect adaptations to different environments in which the languages are learned and used. The aspects of the environment that could shape language include the social, the physical, and the technological. (Lupyan y Dale 2016: I)

Como ha quedado reflejado en el modelo de la figura I, cada lengua tiene un componente cultural (interiorizado del entorno) que es susceptible de cambio y, por tanto, de variación en relación con factores externos (esto es, de adaptación) tales como los mencionados por Lupyan y Dale. Sin embargo, afirmaciones como esta también sugieren que el proceso de adaptación sería central o capital para la adecuada comprensión de la estructura de las lenguas y de su tipología, y esa conclusión es la que he pretendido descartar en esta aportación. Sin duda, muchos y muy diversos factores externos a las lenguas-i han podido dejar su impronta en sus sistemas de exteriorización, pero no creo que esto en sí mismo nos autorice a afirmar que la estructura de las lenguas humanas sea esencialmente un asunto de adaptación al entorno.

\section{REFERENCIAS BIBLIOGRÁFICAS}

ANDERSEN, H. (I973): "Abductive and deductive change", Language, 49, pp. 567-595.

ASOULIN, Eran (2016): "Language as an instrument of thought", Glossa: A Journal of General Linguistics, I(I), 46. https://doi.org/I0.5334/gjgl.34.

BAKER, Mark (1996): The Polysynthesis Parameter, Oxford: Oxford University Press.

BAKER, Mark (200I): The atoms of language, Nueva York: Basic Books.

BAKER, Mark (2003): "Linguistic differences and language design", Trends in Cognitive Science, 7 , pp. 349-353.

BENTZ Christian y Bodo WINTER (20I3): "Languages with more second language learners tend to lose nominal case", Language Dynamics and Change, 3, pp. I-27.

https://doi.org/IO.I I 63/978900428 I 523_005.

BERWICK, Robert C. y Noam CHOMSKY (20 I I): "The Biolinguistic program: the current state of its development", en A.M. Di Sciullo y C. Boeckx (eds.), The Biolinguistic Enterprise, Oxford: Oxford University Press, pp. I9-4I.

BERWICK, Robert C. y CHOMsky, Noam (2016): Why Only Us, Boston: The MIT Press.

BicKel, Balthasar, Alena WitZlack-MaKareVich, Kamal K. Choudhary, Matthias SCHLESEWSKY e Ina BORNKESSEL-SCHLESEWSKY (2015): "The neurophysiology of language processing shapes the evolution of grammar: Evidence from case marking", PLoS ONE, ıо, 8. https://doi.org/I0.I37I/journal.pone.0 I328I9.

Cercle LinguistiQue de Prague (i 929): “Thèses présentées au Premier Congrès des philologues slaves”, Travaux Linguistiques de Prague, I, pp. 5-29.

CHOMSKY, Noam (1985): Knowledge of Language. Its Nature, Origins and Use, Nueva York: Praeger. 
CHOMSKY, Noam (2007): “Approaching UG from below”, en U. Sauerland y H.-M. Gärtner (eds.), Interfaces + Recursion = Language? Chomsky's Minimalism and the View from Semantics, Berlín: Mouton de Gruyter, pp. I-30. https://doi.org/I0. I 5 I 5/9783 I I0207552-00 I.

CROFT, William (200o): Explaining Language Change. An Evolutionary Approach, London: Longman.

DAHL, Östen (2004): The Growth and Maintenance of Linguistic Complexity, Amsterdam/ Philadelphia: John Benjamins.

DARWIn, Charles (1871): The Descent of Man and Selection in Relation to Sex, London: John Murray.

DARWIN, Charles (2000 [1 893]): The Autobiography of Charles Darwin, Amherst: Prometheus Books.

De Busser, Rick y Randy J. LAPOlla (eds.) (2015): Language Structure and Environment: Social, Cultural, and Natural Factors, Amsterdam/Philadelphia: John Benjamins.

DiXON, R. M. W. (I994): Ergativity, Cambridge: Cambridge University Press.

DiXON, R. M. W. (1997): The Rise and Fall of Languages, Cambridge: Cambridge University Press.

Dryer, Matthew S. y Martin Haspelmath (eds.) (2013): The World Atlas of Language Structures Online, Leipzig: Max Planck Institute for Evolutionary Anthropology. http://wals.info.

EVANS, Nicholas y Stephen C. LEVINSON (2009): "The myth of language universals: Language diversity and its importance for cognitive science", Behavioral and Brain Sciences, 32, pp. 429-448. https://doi.org/IO.IOI7/so I 40525x0999094x.

Everett, Caleb, Damián E. Blasí y Seán G. ROBerTs (2016): "Language evolution and climate: the case of desiccation and tone", Journal of Language Evolution, I, pp. 33-46. https://doi.org/ I0.1093/jole/lzvoo4.

Everett, Daniel L. (2005): "Cultural Constraints on Grammar and Cognition in Pirahâ", Current Anthropology, 46, pp. 62I-646. https://doi.org/Io.1086/43 I 525.

Gould, Stephen Jay (1996): “The pattern of life's history”, en John Brockman (ed.), The Third Culture. Beyond the Scientific Revolution, New York: Simon \& Schuster.

Gould, Stephen Jay (2002): The Structure of Evolutionary Theory, Cambridge (MA): Harvard University Press.

Gould, Stephen Jay y Richard C. LEWOnTIN (I979): “The spandrels of San Marco and the panglossian paradigm: A critique of the adaptationist programme", Proceedings of the Royal Society of London, 205, pp. 58 I-598. https://doi.org/I0.1098/rspb. I979.0086.

HARRIS, Alice (2008): "On the explanation of typologically unusual structures", en J. Good (ed.), Linguistic Universals and Language Change, Oxford: Oxford University Press, pp. 54-76. https://doi.org/10.1093/acprof:oso/9780199298495.003.0003.

HaSPELMATH, Martin (2008): "Parametric versus functional explanations of syntactic universals", en Teresa Biberauer (ed.), The Limits of syntactic variation, Amsterdam: John Benjamins, pp. 75-107. https://doi.org/I0.1075/la.I32.04has.

Hauser, Marc D., Noam ChOMSKY y W. Tecumseh FITCH, (2002): "The faculty of language: What is it, who has it, and how it evolved?", Science, 298, pp. I $569-\mathrm{I} 579$.

HAWKINS, John A. (2004): Efficiency and Complexity in Grammars, Oxford: Oxford University Press.

Kauffman, Stuart A. (1993): The Origins of Order. Self-Organization and Selection in Evolution, London: Oxford University Press. 
KAYNE, Richard (I994): The Antysymmetry of Syntax, Cambridge (MA): The MIT Press.

KIPARSKY, Paul (2008): "Universals constrain change; change results in typological generalizations", en J. Good (ed.), Linguistic Universals and Language Change, Oxford: Oxford University Press, pp. 23-53. https://doi.org/10.1093/acprof:oso/9780199298495.003.0002.

KOERnER, Konrad, ed. (1983): Linguistics and Evolutionary Theory. Three Essays by August Schleicher, Ernst Haeckel, and Wilhelm Bleek, Amsterdam/Philadelphia: John Benjamins.

LABOV, William (1963): "The social motivation of a sound change", Word, 19, pp. 273-309.

LADD, Robert D., Séan G. ROBERTS y Dan DEDIU (2015): “Correlational studies in typological and historical linguistics”, Annual Review of Linguistics, I, pp. 22 I-4I.

https://doi.org/IO.I I 46/annurev-linguist-0305 I 4-I 248 I 9.

LASS, Roger (1997): Historical Linguistics and Language Change, Cambridge: Cambridge University Press.

LONGOBARDI, Giuseppe (2003): "Methods in parametric linguistics and cognitive history", Linguistic Variation Yearbook, 3, pp. IоI-I 38.

LUPYAN Gary y Rick DALE (2010): "Language structure is partly determined by social structure”, PLoS ONE 5, I, e8559. https://doi.org/I0.1371/journal.pone.0008559.

LUPYAN, Gary, y Rick DALE (2016): "Why are there different languages? The role of adaptation in linguistic diversity", Trends in Cognitive Sciences, 20(9), pp. 649-66o. https://doi.org/ro. Io $6 /$ j.tics.2016.07.005.

MAYR, Ernst (1942): Systematics and the Origin of Species from the Viewpoint of a Zoologist, New York: Columbia University Press. https://doi.org/I0. I I63/19552629-00502004.

MCWhorTer, John H. (201 I): Linguistic Simplicity and Complexity. Why Do Languages Undress?, Boston/Berlin: The Gruyter Mouton.

MENDíVIL-GIRÓ, José-Luis (2006): "Languages and species: Limits and scope of a venerable comparison”, en J. Rosselló y J. Martín (eds.), The Biolinguistic Turn. Issues on Language and Biology, Barcelona: Promociones y Publicaciones Universitarias, pp. 82-I I 8.

MENDÍVIL-GIRÓ, José-Luis (20I4): "What are languages? A biolinguistic perspective", Open Linguistics, I, pp. 7I-95. https://doi.org/10.2478/opli-2014-0005.

MENDíVIL-GIRÓ, José-Luis (2015): El cambio lingüistico. Sus causas, mecanismos y consecuencias, Madrid: Síntesis.

MENDÍVIL-GIRÓ, José-Luis (20I6): “¿Qué relación hay entre el cambio lingüístico y la evolución del lenguaje?”, Lingüistica en la Red, I4, pp. I-I7.

MENDÍVIL-GIRÓ, José-Luis (20 I8): “Why don't languages adapt to their environment?”, Frontiers in Communication, 3(24). https://doi.org/I0.3389/fcomm.2018.00024.

NeTTLE, Daniel (1999): Linguistic Diversity, Oxford: Oxford University Press.

Nevins, Andrew, David PesETSKY y Cilene Rodrigues (2009): "Pirahã exceptionality: A reassessment”, Language, 85, pp. 355-404. https://doi.org/10.1353/lan.o.0107.

NEWMEYER, Frederick J. (1998): Language Form and Language Function, Cambridge (MA), The MIT Press. 
NEWMEYER, Frederick J. (2003): "Formal and functional motivation for language change", en R. Hickey (ed.), Motives for Language Change, Cambridge: Cambridge University Press, pp. I 8-36. https://doi.org/I0. IoI7/cbo97805 I I 486937.003.

NeWMeYer, Frederick J. (2005): Possible and Probable Languages. A Generative Perspective on Linguistic Typology, Oxford: Oxford University Press.

NiCHOLS, Johanna (1992): Linguistic Diversity in Space and Time, Chicago: University of Chicago Press.

O'Grady, William (2005): Syntactic carpentry: An emergent approach to syntax, Mahwah (NJ): Lawrence Erlbaum.

PERKINS, Revere D. (I988): “The covariation of culture and grammar”, en Michael Hammond, Edit Moravcsik y Jessica Wirth (eds.), Studies in Syntactic Typology, Amsterdam/Philadelphia: Benjamins, pp. 359-378.

PINKER, Steven (2007): "Response to Recursion and human thought: why the Pirahã don't have numbers", A talk with Daniel L. Everett". https://www.edge.org/conversation/recursion-and-humanthought (25/9/2017).

REgIER, Terry, Alexandra CARSTENSEN y Charles KeMP (2016): "Languages support efficient communication about the environment: Words for snow revisited", PLoS ONE, I I (4), eo I 5 I I 38. https://doi.org/I0.1371/journal.pone.0 I 5 I I 38 .

RichardS, Norvin (2016): Contiguity Theory, Cambridge MA: The MIT Press.

RoberTs, Ian y Anna Roussou (2003): Syntactic Change. A Minimalist Approach to Grammaticalization, Cambridge: Cambridge University Press.

SCHLEICHER, August (1983 [1863]): Darwinism Tested by the Science of Language (trad. J. C. Hotten), en Konrad Koerner (ed.), Linguistics and Evolutionary Theory. Three Essays by August Schleicher, Ernst Haeckel, and Wilhelm Bleek, Amsterdam/Philadelphia: John Benjamins, pp. 13-72. Edición original: Die Darwinsche Theorie und die Sprachwissenschaft, Weimar: H. Böhlau.

SEELY, Jonathan (1977): “An ergative historiography”, Historiographia Linguistica, 4(2), pp. I9 I-206.

Swadesh, Morris (1971): The Origin and Diversification of Language, London: Routledge and Kegan Paul.

WilliamS, George C. (1992): Natural Selection: Domains, Levels and Challenges, Oxford: Oxford University Press.

ZAWISZEWSKI, Adam (2017): "Processing ergativity: behavioral and electrophysiological evidence", en J. Coon, D. Massam y L. Travis (eds.), The Oxford Handbook of Ergativity, Oxford: Oxford University Press, pp. 693-708. https://doi.org/Io.1093/oxfordhb/9780198739371.013.28. 